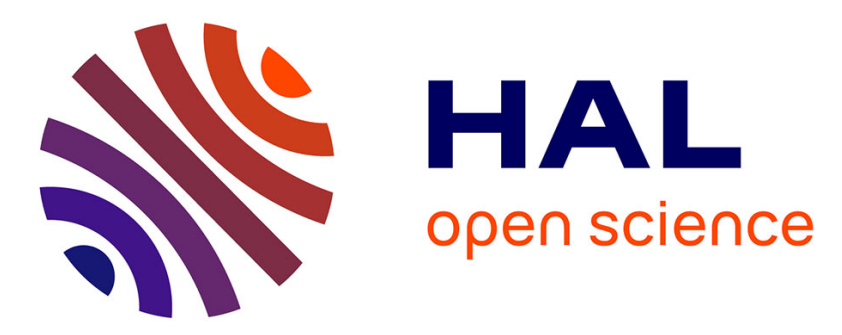

\title{
Shear and extensional properties of short glass fiber reinforced polypropylene
}

Christophe Mobuchon, Pierre J. Carreau, Marie-Claude Heuzey, Maryam

Sepehr, Gilles Ausias

\section{To cite this version:}

Christophe Mobuchon, Pierre J. Carreau, Marie-Claude Heuzey, Maryam Sepehr, Gilles Ausias. Shear and extensional properties of short glass fiber reinforced polypropylene. Polymer Composites, 2005, 26 (3), pp.247-264. 10.1002/pc.20088 . hal-01007284

\section{HAL Id: hal-01007284 \\ https://hal.science/hal-01007284}

Submitted on 20 Nov 2017

HAL is a multi-disciplinary open access archive for the deposit and dissemination of scientific research documents, whether they are published or not. The documents may come from teaching and research institutions in France or abroad, or from public or private research centers.
L'archive ouverte pluridisciplinaire HAL, est destinée au dépôt et à la diffusion de documents scientifiques de niveau recherche, publiés ou non, émanant des établissements d'enseignement et de recherche français ou étrangers, des laboratoires publics ou privés. 


\title{
Shear and Extensional Properties of Short Glass Fiber Reinforced Polypropylene
}

\author{
Christophe Mobuchon, Pierre J. Carreau, Marie-Claude Heuzey, Maryam Sepehr \\ Center for Applied Research on Polymers and Composites (CREPEQ), Chemical Engineering Department, \\ Ecole Polytechnique, P.O. Box 6079, Stn Centre-Ville, Montreal, QC H3C 3A7, Canada
}

\author{
Gilles Ausias \\ LG2M, Université de Bretagne Sud, Rue de St Maudé, BP 92116, 56321 Lorient Cedex, France
}

\begin{abstract}
Shear and extensional properties of a commercial short glass fiber reinforced polypropylene were carefully investigated using commercial rheometers and a novel on-line rheometer. This on-line slit rheometer, installed on an injection molding press, has been designed to measure the steady shear viscosity, the first normal stress difference, and the apparent extensional viscosity of polymer melts and composites for high strain rates up to $10^{5} \mathrm{~s}^{-1}$ in shear and $200 \mathrm{~s}^{-1}$ in extension. Our results show that the steady-state viscosity measurements using the on-line rheometer are in excellent agreement with those obtained using commercial rheometers. The steady-state and the complex viscosities of the composites were found to be fairly close to that of the matrix, but the Cox-Merz rule was not verified for the composites at high rates. The elasticity of the composites was found to be equal to that of the polypropylene matrix. The apparent extensional viscosity was obtained from the pressure drop in the planar converging die of the slit rheometer using the analyses proposed by Cogswell [1] and Binding [2]. The extensional viscosity of the polypropylene was found to be much larger than the shear viscosity at low strain rates with a Trouton ratio of about 40 that decreased rapidly with increasing strain rate down to the value of 4 at $200 \mathrm{~s}^{-1}$. The extensional viscosity of the composites was also found to be close to that of the matrix, with values 35 and $5 \%$ larger for the $\mathbf{3 0}$ and 10 wt $\%$ reinforced polypropylenes, respectively. These results are compared with the predictions of the Goddard model [3], which are shown to overpredict our experimental results. POLYM. COMPOS., 26:247-264, 2005. () 2005 Society of Plastics Engineers
\end{abstract}

Correspondence to: M.-C. Heuzey; e-mail: marie-claude.heuzey@ polymtl.ca

Contract grant sponsor: Natural and Engineering Research Council of Canada (NSERC).

DOI 10.1002/pc.20088

Published online in Wiley InterScience (www.interscience.wiley.

com).

C) 2005 Society of Plastics Engineers

\section{INTRODUCTION}

Composite materials such as polypropylene reinforced with glass fibers are used more and more in the automotive and other manufacturing industries. Glass fiber reinforcement is often an attractive way to improve the mechanical properties of thermoplastics, the improvement being attributed to the excellent mechanical properties of the fibers and to the better adhesion between the fibers and the polymer matrix when surface treated fibers are used [4]. The enhancement of the mechanical properties depends on the fiber lengths and the fiber macro-structure, i.e., the fiber orientation and distribution induced during processing [5]. The nucleating ability of the fibers inducing a transcrystallization of the matrix plays also a key role $[6,7]$. The correct prediction of any macro-structure development during flow using a simulation software requires an accurate rheological description of these reinforced polymers. Although numerous studies have been done, as shown below, on the rheological behavior of these materials, the literature lacks of a comprehensive understanding of the rheological properties of fiber composites, mainly transient and extensional properties. Moreover, there are many contradictions in the literature on the rheological properties of fiber composites.

\section{RHEOLOGICAL OBSERVATIONS}

The steady shear properties at low shear rates of short glass fiber suspensions in Newtonian media have been studied by Goto et al. [8]. They found that the volume fraction, the aspect ratio, and the flexibility of the fibers increased the shear viscosity, especially at low shear rates. Kitano and Kataoka [9] outlined that this shear rate dependence was more pronounced for larger fiber concentrations and larger fiber aspect ratios whereas Gananie and Powell [10] did not observe more shear-thinning effects for fiber suspensions, but their data have been obtained for lower shear rates and for smaller fiber aspect ratios. The same tendencies as noted 
by Goto et al. [8] for Newtonian suspensions have been reported for short fiber suspensions in viscoelastic media [10-14]. Most of the authors cited above did not examine or mention the state of the fiber macro-structure. Milliken et al. [15] and Mondy et al. [16] using falling ball rheometry have shown that shear viscosity decreased as the fibers aligned in the flow direction. High-shear-rate capillary data [13, 1719] have indicated also that the fiber orientation depended on the shear rate and, in particular, fiber alignment in the flow direction increased with residence time and the flow rate and decreased with fiber concentration [18, 19]. The evolution of the fibers macro-structure at low frequencies during the dynamic shear measurements is cited by Kitano et al. [13] to explain the failure of the Cox-Merz rule. They found that the storage and loss moduli increased with fiber content and observed for the moduli at high frequencies short plateaus, which they explained by an evolution of the fiber macro-structure. The study of Kim and Song [20] supports this assumption of evolution of the macro-structure during a frequency sweep test. They observed that the complex viscosity decreased with increasing strain amplitude, frequency, and time. From a theoretical point of view, Harlen and Koch [21] justified the observations of Kim and Song [20]. Their simulations based on an Oldroyd-B fluid, confirmed by the experimental study of Petrich et al. [22], showed that fibers could be aligned by an oscillatory shear flow. Goto et al. [8] and Kitano and Kataoka [9] measured non zero steady-shear first normal stress differences for fiber suspensions in inelastic Newtonian fluids. Zirnsak et al. [23] verified that the loss angle was not affected by the fiber content and they concluded that the measured normal stress differences did not reflect the elastic behavior of those suspensions but the fiber-fiber interactions. Chan et al. [11], Czarnecki and White [12], Greene and Wilkes [14], Kitano et al. [13], Barbosa and Kataoka [24], and Sepehr et al. [25] concluded in the same manner. Sepehr et al. [25] have also shown that the relaxation of the shear and normal stresses of glass fiber suspensions in a Newtonian and elastic matrices following steady-shear flow was not affected by fiber content, indicating that the elasticity of the suspensions is that of the matrix.

Finally, the apparent extensional viscosity of fiber reinforced polymers was measured at low strain rates, from $10^{-3}$ $\mathrm{s}^{-1}$ to $10 \mathrm{~s}^{-1}[11,26-28]$, using fiber spinning instruments $[29,30]$. Values for the extensional viscosity 1 to 20 times greater than the neat polymer were obtained depending on the volume fraction of the fibers and the extensional strain rate. Moreover, Chan et al. [11] observed a decreasing extensional viscosity of the reinforced polymers with extensional rate although the extensional viscosity of their neat polymer was constant over the same range of extensional rate.

\section{Extensional Stress Predictions}

Several constitutive models for fiber reinforced systems have been developed for semi concentrated systems [31-
33]. For an extensional flow of a diluted or semi-concentrated suspension of aligned fibers in a Newtonian fluid, Batchelor [33] applied his body slender theory and obtained the following expression for the intrinsic particle stress:

$$
[\sigma]=\frac{2}{9} \frac{r^{2}}{\ln (\beta)}
$$

where $[\sigma]$, the intrinsic particle stress, is defined by:

$$
[\sigma(\dot{\varepsilon})]=\frac{\sigma(\dot{\varepsilon})-\sigma_{0}(\dot{\varepsilon})}{\sigma_{0}(\dot{\varepsilon}) \phi_{\nu}}
$$

with $\beta=\sqrt{\pi / \phi_{\nu}}, \sigma_{0}$ the tensile stress in the pure polymer, $\sigma$ the tensile stress in the suspension, $r$ the fiber aspect ratio, $\phi_{\mathrm{v}}$ the volume fraction of fibers, and $\dot{\varepsilon}$ the extensional rate.

Shaqfeh and Fredrickson [32] improved this analysis, which was afterwards extended for a power-law fluid by Goddard [3]:

$$
[\sigma]=\frac{2}{9} r^{1+n}\left[\frac{\frac{1}{n}-1}{1-\beta^{1-(1 / n)}}\right]^{n} B
$$

where $B=(9 / 2+n) \eta_{e}(\dot{\varepsilon}) / \eta(\dot{\varepsilon})$ only if $r \gg \beta \gg 1, n$ is the power-law index, $\eta$ and $\eta_{e}$ are the shear and the extensional viscosity, respectively, of the matrix.

\section{Objective}

The overall objective of this paper is to report shear and extensional rheological properties of short glass fiber reinforced polypropylene from low to large strain rates. Various commercial rheometers and a novel on-line rheometer mounted on an injection molding machine have been used to obtain the data. Furthermore, the extensional viscosity measurements are compared with the predictions of the Goddard model [3].

\section{EXPERIMENTAL}

\section{Materials}

A 10 and a $30 \mathrm{wt} \%$ short glass fiber reinforced polypropylene and the neat polypropylene used were supplied in pellet form by Basell (Hostacom G3 N01L). The $10 \mathrm{wt} \%$ composite corresponded to the semi-concentrated regime whereas the $30 \%$ composite was in the concentrated regime. For all the samples used in rotational rheometry, a thermal stabilizer (Irganox B225, $1 \mathrm{wt} \%$ ) was added to the material using a Brabender internal mixer (40 RPM for 4 min at $200^{\circ} \mathrm{C}$ ). The test samples were obtained by compression molding at $200^{\circ} \mathrm{C}$. This processing method resulted in a planar random fiber orientation in the sample plane [34]. For the capillary and the on-line rheometry, the pellets were 
TABLE 1. Fiber characteristics.

\begin{tabular}{|c|c|c|c|c|c|c|}
\hline Reference & $\phi_{m} ;(\%)$ & $\phi_{\nu} ;(\%)$ & Mixing method & $\begin{array}{c}L_{w}, \mu \mathrm{m} \\
( \pm 10 \mu \mathrm{m})\end{array}$ & $\begin{array}{c}L_{n}, \mu \mathrm{m} \\
( \pm 10 \mu \mathrm{m})\end{array}$ & $L_{w} / L_{n}$ \\
\hline \multirow[t]{3}{*}{ PP10 } & \multirow[t]{3}{*}{10} & \multirow[t]{3}{*}{3.8} & As supplied & 790 & 610 & 1.3 \\
\hline & & & Injection machine & 660 & 530 & 1.24 \\
\hline & & & Brabender internal mixer & 520 & 440 & 1.18 \\
\hline \multirow[t]{3}{*}{ PP30 } & \multirow[t]{3}{*}{30} & \multirow[t]{3}{*}{13.2} & As supplied & 520 & 430 & 1.2 \\
\hline & & & Injection machine & 400 & 330 & 1.22 \\
\hline & & & Brabender internal mixer & 350 & 300 & 1.15 \\
\hline
\end{tabular}

used as received. A test was also carried out using the capillary rheometer with a stabilized sample blended in the internal mixer. No significant differences were observed between the stabilized and nonstabilized samples. The fiber diameter was $14 \mu \mathrm{m}$ and the fiber lengths are reported in Table 1 in terms of $L_{n}$ and $L_{w}$, the number average and weight average lengths, respectively, defined by:

$$
\begin{gathered}
L_{n}=\frac{\sum_{i} n_{i} L_{i}}{\sum_{i} n_{i}} \\
L_{w}=\frac{\sum_{i} n_{i} L_{i}^{2}}{\sum_{i} n_{i} L_{i}} .
\end{gathered}
$$

The length values of Table 1 are based on the manual measurement of 400 fibers using optical microscopy and image analyzer (Visilog) after pyrolysis of the polymer. The lengths of fibers measured after blending using the internal mixer are the characteristics for the samples used in rotational rheometry, while the lengths measured after injection molding are those of the samples for the on-line measurements. We note from Table 1 that the fiber length was considerably reduced by the processing and depended on the fiber content of the composite. From the samples as received from the supplier, the number average length $L_{n}$ was 610 and $430 \mu \mathrm{m}$ for the 10 and $30 \mathrm{wt} \%$ composite, respectively. After processing through the injection molding machine, the number average length was reduced to 530 and $330 \mu \mathrm{m}$, respectively. The fiber damage was more severe in the internal mixer and the number average length was reduced to 440 and $300 \mu \mathrm{m}$ for the 10 and $30 \mathrm{wt} \%$ composite, respectively. As expected, longer fibers were more easily broken down in processing as indicated by the decreasing ratio of $L_{w} / L_{n}$. The aspect ratio of the fibers was larger than 20 in all cases and we assumed that the differences in length were not sufficient to affect the rheological properties of the fiber reinforced polypropylene composites at high shear rates. However, the observed differences between the average fiber lengths of the 10 and $30 \mathrm{wt} \%$ composites cannot be ignored when examining the effect of fiber content on the properties at low shear rates or in the dynamic mode.

\section{Rotational Rheometry}

Measurements of the linear viscoelastic properties were carried out using three stress controlled rheometers (AR 2000, TA Instruments; CSM, Bohlin Instruments; SR 5000, Rheometric Scientific). The parallel-plate geometry was used instead of the cone-and-plate geometry to avoid wall effects. According to Bibbo et al. [35], wall effects are not significant only when the gap between the parallel plates is much greater than the fiber length, a condition that the cone-and-plate geometry cannot guarantee. The downside of the parallel-plate geometry is that the shear rate is nonhomogeneous but varies linearly with the radial position, and consequently so does the deformation. For all experiments, the gap was set between 1.2 and $1.6 \mathrm{~mm}$ with a plate diameter of $25 \mathrm{~mm}$. To reduce thermal degradation, all measurements were performed under nitrogen. The standard deviations reported (vertical error bars) are based upon three measurements done with fresh samples. Frequency sweep tests were performed from the highest to the lowest frequency in the linear domain. For steady-state measurements we proceeded from low to high shear rates and the torque was averaged during $60 \mathrm{~s}$ for low shear rates and $40 \mathrm{~s}$ for higher values until a constant value within $2 \%$ was obtained. The Rabinowitsch analysis was applied to the parallel plate viscosity data to account for shear-thinning effects [36].

\section{Capillary Rheometry}

High shear rate data were obtained using an Instron rheometer with capillaries of aspect ratios (length to diameter) of 24.6, 35.5, 40, and 80.1 with $1.26 \mathrm{~mm}$ diameter and $90^{\circ}$ entrance angle. The Bagley corrections were found to be negligible, but the Rabinowitsch analysis [36] was applied to the capillary data.

\section{On-Line Rheometry}

To extend the previous data to injection molding conditions, a high strain rate rheometer was constructed and mounted in place of the mold in an all electric injectionmolding machine (Sumitomo SE50S). The injection speed of the Sumitomo SE50S electric injection molding machine ranges from 0.1 to $200 \mathrm{~mm} / \mathrm{s}$. The diameter of its screw is $16 \mathrm{~mm}$ and its rotation speed was set at $100 \mathrm{RPM}$. 


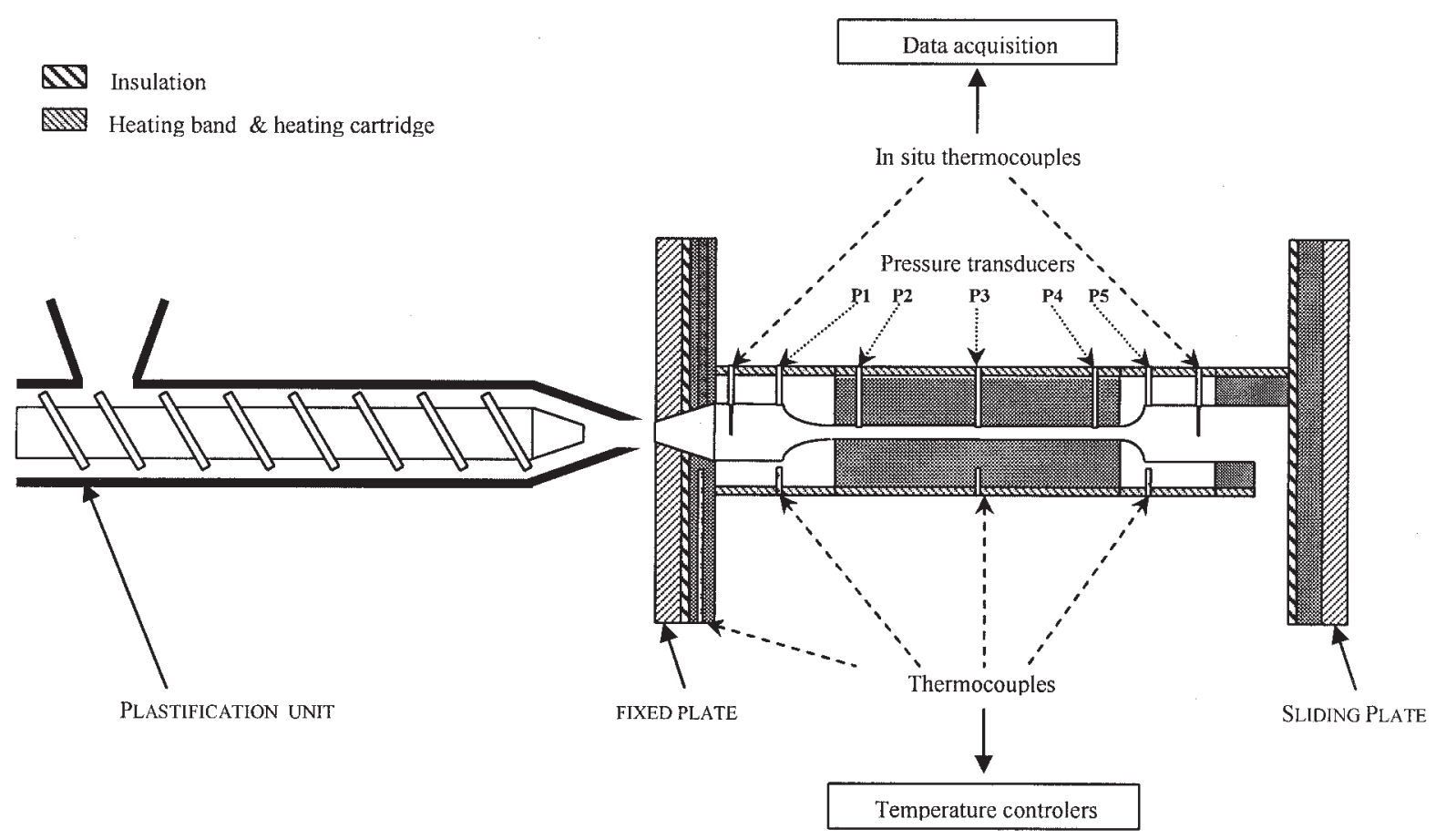

FIG. 1. Schematic of the on-line rheometer.

The on-line rheometer (Fig. 1) consists of a converging die, a slit die, and a diverging die made of steel (dimensions listed in Table 2 for converging and slit dies). The slit die with different gaps is suitable for measuring the shear viscosity, while the converging die is used to obtain the extensional flow behavior. Details about the converging die geometry are given in the following sections. The pressure profile along the rheometer was measured by five flushmounted pressure transducers (Grefan ISI 0101 and Dynisco TPT). The first and the last pressure transducers are located at the entrance of the hyperbolic converging section and of the entrance of the hyperbolic diverging section, respectively. The distance between the pressure transducers mounted on the slit die is equal to $35 \mathrm{~mm}$. The two thermocouples located upstream and downstream of the slit die are used to measure the temperature of the fluid and to control the melt temperature within $2{ }^{\circ} \mathrm{C}$ using two Omega CN491 temperature controllers. All data are sampled at a frequency of $40 \mathrm{~Hz}$ using a data acquisition card (PCI 6034E of National Instruments) with a software developed by Labview.

Two different converging dies have been designed fol- lowing suggestions of Kim et al. [37] and James et al. [38]. If the shape of the converging section is hyperbolic (Fig. 2) a constant extensional rate is obtained. For a planar geometry along the $z$-axis, the average extensional rate, $\langle\dot{\varepsilon}\rangle$, is defined by:

$$
\langle\dot{\varepsilon}\rangle=\frac{d\left\langle V_{z}(y, z)\right\rangle}{d z}=\frac{Q}{4 W} \frac{d}{d z}\left(\frac{1}{h(z)}\right)
$$

where $\left\langle V_{z}(y, z)\right\rangle$ is the average velocity at a given $z, Q$ the volumetric flow rate, $2 h$ the height and $2 W$ the width of the converging die. Imposing a constant average extensional rate results in the following equation, representing a hyperbolic shape:

$$
h(z)=\left(4 \frac{\langle\dot{\varepsilon}\rangle_{\max } W z}{Q_{\max }}+\frac{1}{h_{i}}\right)^{-1}
$$

where $\langle\dot{\varepsilon}\rangle$ is the maximum average extensional rate obtainable corresponding to the maximum flow rate $Q_{\max }$, sup-

\begin{tabular}{|c|c|c|c|c|c|}
\hline Geometry & $\begin{array}{c}\text { Inlet } \\
\text { thickness, } \\
2 h_{0}, \mathrm{~mm}\end{array}$ & $\begin{array}{c}\text { Outlet } \\
\text { thickness, } \\
2 h_{f}, \mathrm{~mm}\end{array}$ & $\begin{array}{l}\text { Width, } 2 W, \\
\text { mm }\end{array}$ & $\begin{array}{l}\text { Length, } L, \\
\text { mm }\end{array}$ & $\begin{array}{l}\text { Strain rate range, } \\
\mathrm{s}^{-1}\end{array}$ \\
\hline Slit die & $2 \& 3.04$ & $2 \& 3.04$ & 25 & 70 & $10^{1}-10^{5}$ \\
\hline Converging die $a$ & 8 & 2 & 25 & 12 & $0.2-200$ \\
\hline Converging die $b$ & 8 & 2 & 25 & 24.1 & $0.1-100$ \\
\hline
\end{tabular}

TABLE 2. Dimensions of the on-line rheometer. 


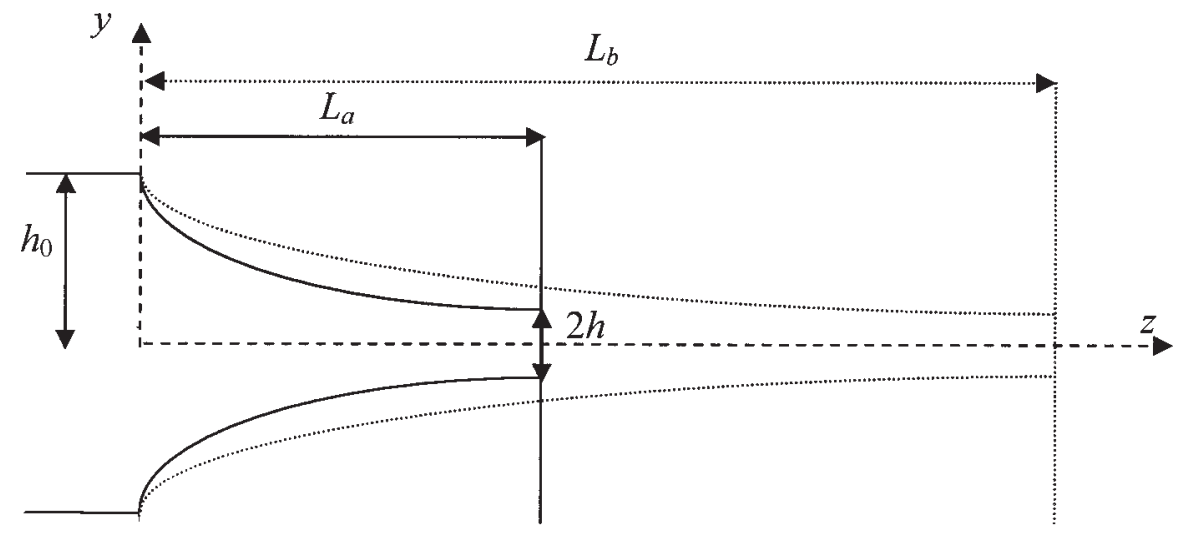

FIG. 2. View of the side cross-section of the two converging dies "a" and "b".

plied by the injection machine. The resulting average extensional rate is then:

$$
\langle\dot{\varepsilon}(Q)\rangle=\frac{Q}{4 W L}\left(\frac{1}{h_{f}}-\frac{1}{h_{0}}\right)
$$

where $h_{0}$ is the initial height, $h_{f}$ the final height, and $L$ the length of the converging die.

\section{Interpretation of Data From the On-Line Rheometry}

Assuming that the side walls of the slit die are of negligible flow resistance, for $2 W \gg 2 h_{f}$, the power-law parameters, $n$ and $m$, can be easily obtained using the following expression for the flow rate as a function of the pressure drop across the slit, $P_{O}-P_{L}[36]$ :

$$
Q=\frac{4 W h^{2}}{\frac{1}{n}+2}\left(\frac{\frac{P_{0}-P_{L}}{L} h}{m}\right)^{1 / n} .
$$

The analyses proposed by Cogswell [1] and Binding [2] have been used to estimate the extensional properties. These approximate methods correlate the flow rate and pressure drop for the flow through a contraction to an apparent extensional viscosity. Except in the case of lubricated flows [37], the flow in a contraction is complex with shear and extensional components. In the Cogswell and Binding methods, the entry flow is separated into shear and extensional components. To measure a meaningful extensional viscosity, the shape of the converging section must be carefully designed. Four interrelated factors need to be examined: the contraction ratio, the homogeneity of the extensional strain rate, the shear and extensional contributions of the total pressure drop, and the residence time. These are discussed in the next three sub-sections.

\section{Cogswell Analysis}

In the Cogswell [1] analysis, the total pressure drop, $\Delta P$, is divided into a shear, $\Delta P_{s}$, and an extensional, $\Delta P_{e}$, term:

$$
\Delta P=\Delta P_{s}+\Delta P_{e}
$$

To estimate the pressure drop due to shear, Cogswell assumed that:

1) the viscosity under simple shear, $\eta$, can be described by a power-law expression:

$$
\eta=m|\dot{\gamma}|^{n-1}
$$

where $\dot{\gamma}$ is the shear rate;

2) the extensional viscosity, $\eta_{e}$, is independent of the applied stress;

3) the flow is laminar, locally fully-developed and under steady state.

The shear contribution for the converging die with geometry defined by Eq. 7 is therefore expressed as:

$$
\begin{aligned}
\Delta P_{s}=\left(\frac{Q(2 n+1)}{4 W n}\right)^{n} & \frac{m L}{2(n+1)\left(\frac{1}{h_{f}}-\frac{1}{h_{0}}\right)} \\
& \times\left[\left(\frac{1}{h_{f}}\right)^{2(n+1)}-\left(\frac{1}{h_{0}}\right)^{2(n+1)}\right] .
\end{aligned}
$$

For the contribution of the extensional flow component, Cogswell considered an average extensional stress yielding the following expression for the pressure drop:

$$
d P_{e} \approx\left\langle\sigma_{z z}\right\rangle d \varepsilon=\eta_{e}\langle\dot{\varepsilon}\rangle d \varepsilon
$$

where $d \varepsilon$ is the extensional strain taken as $d h / h$. Hence, 


$$
\begin{aligned}
\Delta P_{e} \approx-\int_{h_{0}}^{h_{f}}\left\langle\sigma_{z z}\right\rangle \frac{d h(z)}{h(z)}=-\int_{h_{0}}^{h_{f}} \eta_{e}\langle\dot{\varepsilon}\rangle \frac{d h(z)}{h(z)} & \\
& =-\eta_{e}\langle\dot{\varepsilon}\rangle \int_{h_{0}}^{h_{f}} \frac{d h(z)}{h(z)} .
\end{aligned}
$$

Finally, for a hyperbolic-shaped die the pressure drop due to the extensional flow component is given by:

$$
\Delta P_{e} \approx \eta_{e} \frac{Q}{4 W L}\left(\frac{1}{h_{f}}-\frac{1}{h_{0}}\right) \ln \left(\frac{h_{o}}{h_{f}}\right)
$$

The apparent extensional viscosity can be easily calculated from the experimental pressure drop once the powerlaw parameters for the shear viscosity are known.

\section{Binding Analysis}

Unlike Cogswell, Binding [2] used an energy balance and expressed the extensional viscosity as a power-law function of the extensional rate $\left(\eta_{e}=l \varepsilon^{t-1}\right)$. He derived the following expression for the power consumption, $\dot{E}$, for the flow in a converging planar die:

$$
\begin{gathered}
\dot{E}=m Q\left[\frac{Q(2 n+1)}{4 W n}\right]_{0}^{n} \frac{1}{h(z)^{2 n+1}} d z \\
+4 W l J_{n t}\left[\frac{Q(2 n+1)}{4 W(n+1)}\right]^{t+1} \int_{0}^{L} h(z) \\
\times\left[\frac{1}{h(z)^{2}}\left(-\frac{d h(z)}{d z}\right)\right]^{t+1} d z \\
+\frac{\rho(2 n+1)^{2} Q^{3}}{6(3 n+2)(4 n+3) W^{2}} \int_{0}^{L} \frac{1}{h(z)^{3}}\left(-\frac{d h(z)}{d z}\right) d z
\end{gathered}
$$

with:

$$
J_{n t}=\int_{0}^{1}\left[\operatorname{abs}\left\{1-\left(\frac{2 n+1}{n}\right) \phi^{1+(1 / n)}\right\}\right]^{1+t} d \phi
$$

The first and last terms of the power consumption expression $(E q .16)$ are the contributions from the shear component, $\dot{E}_{s}$, and from inertia, respectively. They can be easily estimated if the shear behavior of the fluid and the profile of the converging section are known. The extensional parameters, $l$ and $t$, are then obtained from the plot of the extensional contribution, $\dot{E}_{e}=Q \Delta P_{e}$, as a function of the flow rate. The extensional rate in the analysis of Binding [2] is a variable given by the following expression:

$$
\begin{aligned}
\dot{\varepsilon}=\frac{Q(2 n+1)}{4 W(n+1)}\left\{\left(\frac{2 n+1}{n}\right)\left(\frac{y}{h}\right)^{1+1 / n}-1\right\} & \\
& \times \frac{1}{h(z)^{2}}\left(-\frac{d h(z)}{d z}\right) .
\end{aligned}
$$

In our case of a constrained convergence in a hyperbolic die, the maximum extensional rate (at the center line) is related to the average extensional rate used in the Cogswell analysis (Eq. 6) by the following:

$$
\dot{\varepsilon}_{\max }=\frac{(2 n+1)}{(n+1)}\langle\dot{\varepsilon}\rangle
$$

Since the effect of the extensional flow is confined to the central region of the converging die, $\dot{\varepsilon}_{\max }$ will be used to report the extensional viscosity calculated using the Binding analysis.

As pointed out by Binding [2], his analysis is based on the assumptions that the transverse velocity components are negligible and that the fluid elasticity will not significantly contribute to the pressure drop in the converging section. Finally, the analysis is applicable to constrained converging flows using the die profile, $h(z)$, provided that the convergence angle of the hyperbolic die is not larger than that of the vortex generated in free convergence (case of a sudden contraction).

\section{Residence Time in a Hyperbolic Converging Die}

The residence time, $t_{R}$, can be defined by the following equation:

$$
t_{R}=\int_{0}^{L} \frac{1}{\left\langle V_{z}\right\rangle} d z=\frac{4 W}{Q} \int_{0}^{L} h(z) d z
$$

with:

$$
\left\langle V_{z}\right\rangle=\frac{Q}{4 W h(z)}
$$

So, for hyperbolic converging dies, defined by Eq. 7, the residence time is:

$$
\begin{aligned}
t_{r}=\frac{Q_{\max }}{\langle\dot{\varepsilon}\rangle_{\max } Q} \ln \left(1+4 \frac{W\langle\dot{\varepsilon}\rangle_{\max } L h_{0}}{Q_{\max }}\right) \\
=\frac{1}{\langle\dot{\varepsilon}\rangle} \ln \left(1+4 \frac{W\langle\dot{\varepsilon}\rangle L h_{0}}{Q}\right) .
\end{aligned}
$$

\section{Design of the Two Converging Dies Used in This Study}

For the purpose of this study two hyperbolic converging dies were designed with two different lengths as reported in Table 2. The range for the extensional rate is $0.2-200 \mathrm{~s}^{-1}$ for 


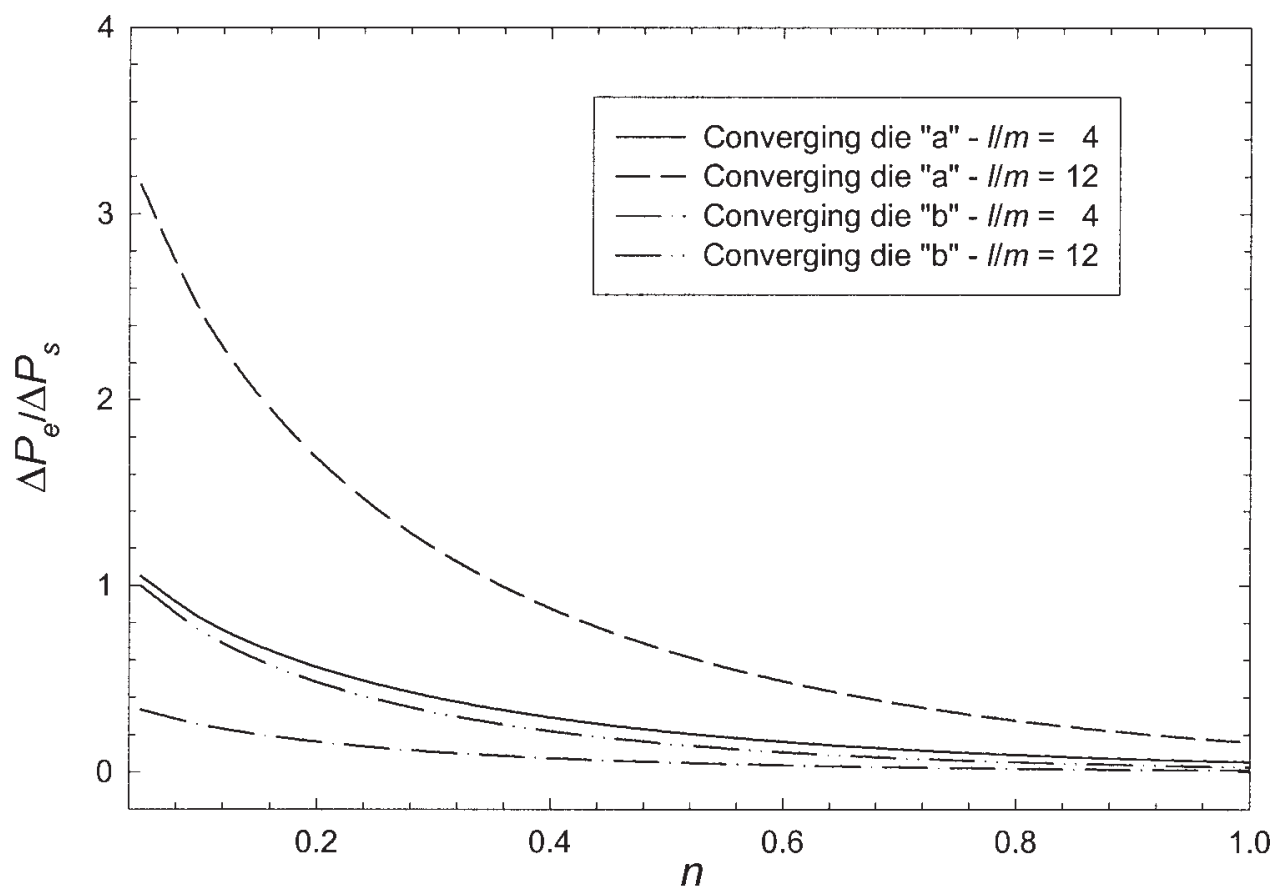

FIG. 3. Ratio of extensional flow and shear flow contributions to the pressure drop for the converging dies "a" and " $\mathrm{b}$ " according to the Binding analysis with $\mathrm{n}=\mathrm{t}$.

the shorter die and $0.1-100 \mathrm{~s}^{-1}$ for the longest one. However, the residence time (Eq. 22) for a specific extensional rate is the same for both dies. For a shear-thinning fluid, Eqs. 12 and 15 of the Cosgwell analysis can be used to calculate the ratio of the pressure drop for the two dies due to the shear and extensional contributions, respectively:

$$
\frac{\left.\Delta P_{s \text { converging die } b}\right|_{\dot{\varepsilon}}}{\left.\Delta P_{s \text { converging die } a}\right|_{\dot{\varepsilon}}}=2^{n+1}
$$

and

$$
\frac{\left.\Delta P_{e \text { converging die } b}\right|_{\dot{\varepsilon}}}{\left.\Delta P_{e \text { converging die } a}\right|_{\dot{\varepsilon}}}=1
$$

The two converging dies give rise to the same extensional contribution but differ in their shear pressure drop contribution, which is more than double for the long converging die $(b)$ compared to the shorter one $(a)$.

The ratio of the extensional contribution, $\dot{E}_{e}$, and the shear contribution, $\dot{E}_{s}$, has been calculated using the Binding analysis (Eq. 16) for the two converging dies, and the results are reported in Fig. 3 in terms of pressure drop ratio as a function of the power-law index, assuming $n=t$. Two different Trouton ratios were considered, $l / m=4$ and $l / m$ $=12$. As expected, the extensional contribution is more important for the shorter die and for the larger Trouton ratio. It is interesting to note that the extensional contribution with respect to the shear contribution increases markedly as the shear-thinning character of the fluid becomes more pronounced (smaller power-law index).

\section{RESULTS AND DISCUSSION}

First, we verified that the wall slip effects were not significant for the parallel-plate and the on-line measurements. For both geometries we applied the Yoshimura and Prud'homme method [39] and no significant effects of the gap could be observed. Similar measurements were carried out with reinforced systems to investigate possible wall fiber interactions. It appeared that a ratio of the gap and fiber length close to 3 was sufficient to avoid significant wall effects. This ratio is greater than the limiting ratio of 1 suggested by Bibbo et al. [35].

The contribution of the lateral walls to the total pressure drop for the on-line rheometer was quantified numerically. The analytical expressions presented in the previous section, from which are obtained the shear and extensional viscosities, are 1D analyses that do not take into account the effect of the lateral walls. These walls represent $7.4 \%$ and $12.5 \%$ of the total surface areas for the slit and the converging dies, respectively. Hence, the lateral walls could contribute significantly to the total pressure drop, at least for the two converging dies. Flows (2D and 3D) for the on-line rheometer were computed using the finite element software packages Poly $2 \mathrm{D}^{\mathrm{TM}}$ and Poly $3 \mathrm{D}^{\mathrm{TM}}$ to assess the contribution of the lateral walls. The fluid was assumed to be inelastic and its viscosity described by the Carreau three-parameter model [36]; the simulations were carried out for a flow rate of $100 \mathrm{~mL} / \mathrm{s}$ 
with the model parameters describing the polypropylene used in this work. In all cases, the pressure drop induced by the lateral walls of the slit die and of the converging section compared with the main walls represents less than $7 \%$, confirming the previous results of Mourniac et al. [40]. The assumption of negligible lateral wall effects for the on-line rheometer is therefore justified.

\section{Linear Viscoelastic Properties}

As expected, the reinforced systems exhibited a nonlinear viscoelastic behavior down to very low strain amplitudes. However, we determined the linear region, which extended as far as the variation of the complex viscosity was less than $5 \%$ for a frequency of $0.628 \mathrm{rad} / \mathrm{s}$. Consequently, for the frequency sweep tests, a strain amplitude of 0.05 was used for the neat polypropylene and the $10 \mathrm{wt} \%$ reinforced polypropylene, whereas a lower strain amplitude of 0.005 was used for the $30 \mathrm{wt} \%$ composite.

The effects of fiber concentration on the complex viscosity, $\eta^{*}$, and on the dynamic storage modulus, $G^{\prime}$, are shown in Fig. 4 for samples that had not been presheared before the test. We note that the behavior of $\eta^{*}$ (Fig. 4a) and $G^{\prime}$ (Fig. 4b) is typical of homogeneous polymer melts. The properties of the $10 \mathrm{wt} \%$ (semidilute) composite are close to those of the neat polymer, but significant enhancements of both dynamic properties are observed for the concentrated fiber suspension (30 wt $\%)$. The increases of $\eta^{*}$ and $G^{\prime}$ are independent of the frequency and the out-of-phase angle, $\delta\left(\tan [\delta]=G^{\prime \prime} / G^{\prime}\right)$ is shown in Fig. 5 to be independent of the fiber content. This indicates that the elasticity of the suspensions is that of the matrix. A similar observation was recently reported by Hashemi et al. [41] for a Kraft (paper) fiber reinforced polypropylene. However, our $G$ ' data do not depict the plateau behavior at intermediate frequencies observed by Kitano et al. [42].

The previous results were obtained with tests samples prepared by compression molding. This process leads to an isotropic fiber orientation in the plane perpendicular to the disk axis (orthotropic orientation). As shown by Laun and Schuch [43] and Ausias et al. [34], the orientation state of the fibers macro-structure can be modified by a creep test. Figure 6 shows how a creep test, carried out until steady state was reached and applied before the frequency sweep test, affected the complex viscosity of the $30 \mathrm{wt} \%$ reinforced polypropylene. The relative complex viscosity, $\Delta \eta_{r}^{*}$ defined by

$$
\Delta \eta_{r}^{*}(\omega)=\left.\frac{\eta_{\text {suspension }}^{*}-\eta_{\text {matrix }}^{*}}{\eta_{\text {matrix }}^{*}}\right|_{\omega}
$$

decreased with pre-shearing independently of the frequency. We note from Fig. 6 that the complex viscosity of the non-sheared sample is approximately twice that of the matrix. The complex viscosity of the $30 \mathrm{wt} \%$ com- posite dropped to 1.68 and 1.43 of that of the matrix after pre-shearing at a stress of 500 and $1000 \mathrm{~Pa}$, respectively. Finally, the out-of-phase angle is shown in Fig. 5 to be independent of the fiber content and pre-shearing. This indicates that the characteristic elastic time of the composites, defined by Ref. 36:

$$
\lambda=\frac{G^{\prime}}{G^{\prime \prime} \omega}=\frac{1}{(\tan \delta) \omega}
$$

is independent of fiber content and is equal to that of the matrix, confirming the findings of Hashemi et al. [41] for a different composite and Sepehr et al. [25] for the same composite.

\section{Steady Shear Data}

The steady state viscosity, $\eta$, obtained from rotational rheometry as a function of the shear rate for different fiber contents is shown in Fig. 7. The viscosity behavior of the composites is similar to that of the matrix, but the increase with fiber content was more important at low shear rates, in contrast to the complex viscosity, for which the increases was about independent of the frequency (Fig. 6). However, the steady shear viscosity data were obtained for shear rates down to $10^{-3} \mathrm{~s}^{-1}$ that is about a decade lower than the frequency range investigated. We note also that the zeroshear plateau was not reached yet at $10^{-3} \mathrm{~s}^{-1}$ for the $30 \mathrm{wt} \%$ composite.

\section{On-Line Viscosity Data}

The temperature shift factor was applied for the shear viscosities measured with the on-line rheometer to verify how good the temperature control was. The temperature shift factor, $a_{T}$, is defined by the following expression [36]:

$$
a_{T}=\left.\frac{\eta^{*}(T) T_{0} \rho_{0}}{\eta^{*}\left(T_{0}\right) T \rho}\right|_{\omega}
$$

where $T, T_{0}, \rho$ and $\rho_{0}$ are the temperature, the reference temperature, the density, and the density at the reference temperature, respectively. The temperature shift factors used were determined thanks to the Arrhenius relationship:

$$
a_{T}=\exp \frac{E}{R}\left(\frac{1}{T}-\frac{1}{T_{0}}\right)
$$

where $R$ is the universal gas constant and $E$ the flow activation energy. From dynamic data, $E$ was found to be equal to $36.82 \mathrm{~kJ} / \mathrm{mol}$ for the polypropylene for temperatures ranging from 180 to $220^{\circ} \mathrm{C}$ and $T_{0}$ equal to $200^{\circ} \mathrm{C}$. This result is comparable to published values, which range from 36 to $50 \mathrm{~kJ} / \mathrm{mol}$ for polypropylene.

The master curve for the polypropylene is shown in Fig. 

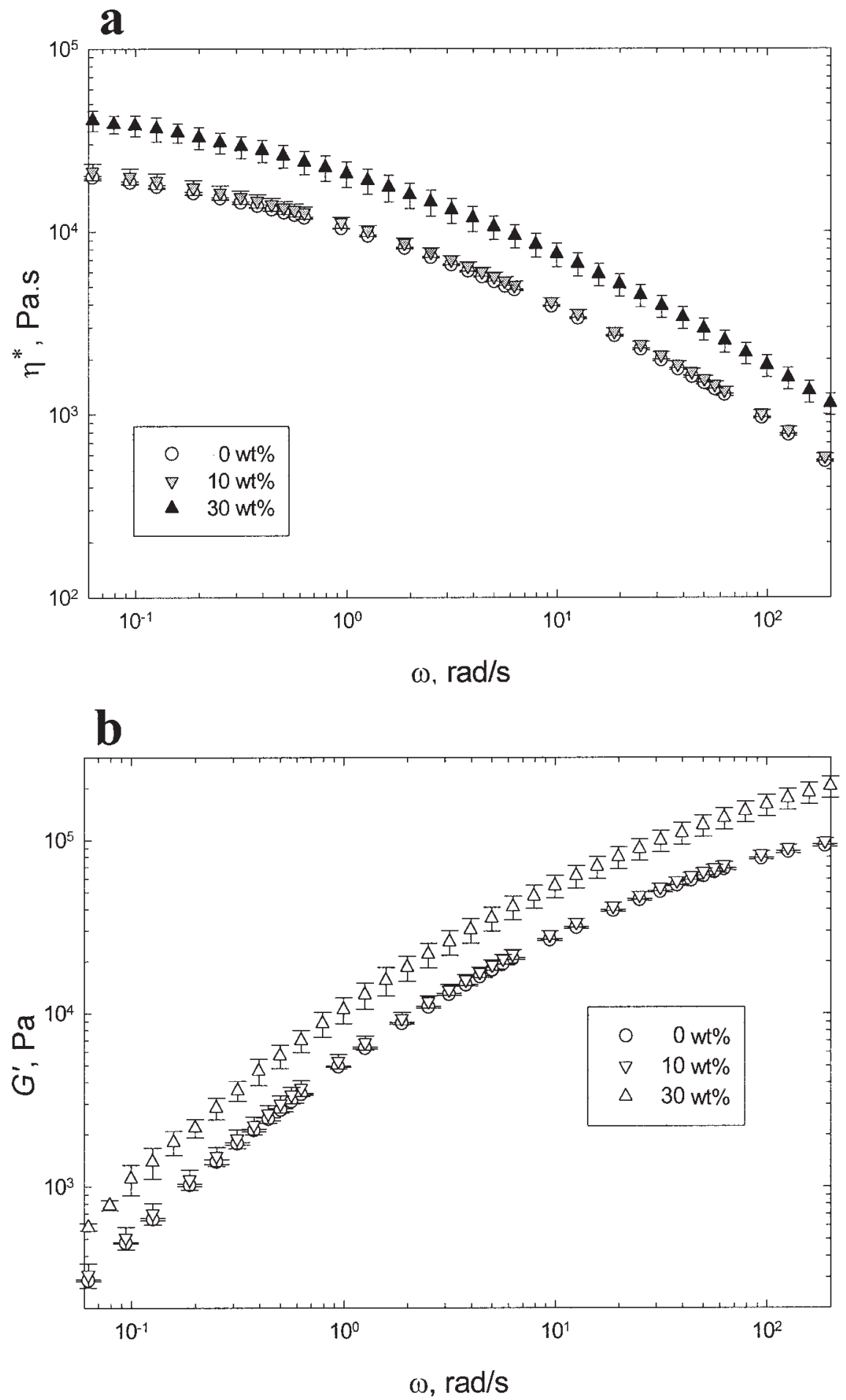

FIG. 4. Complex viscosity $\eta^{*}$ (a) and dynamic storage modulus $G^{\prime}$ (b) vs. frequency $\omega$ for reinforced polypropylene with various fiber contents; $\mathrm{T}=200^{\circ} \mathrm{C}$. The samples had not been pre-sheared before the dynamic measurements.

8. After corrections for the temperature, the viscosity data line up in a smooth curve, indicating that the shift factors used are accurate, i.e., the temperatures assumed to calculate them are accurate, and so that the temperature control during measurements is acceptable.
We are also showing in this figure the data for the 30 wt $\%$ composite obtained at the same three temperatures. The shift factors used were calculated using the same flow activation energy than the neat polypropylene. This is reasonable since the properties of the glass fibers and their 


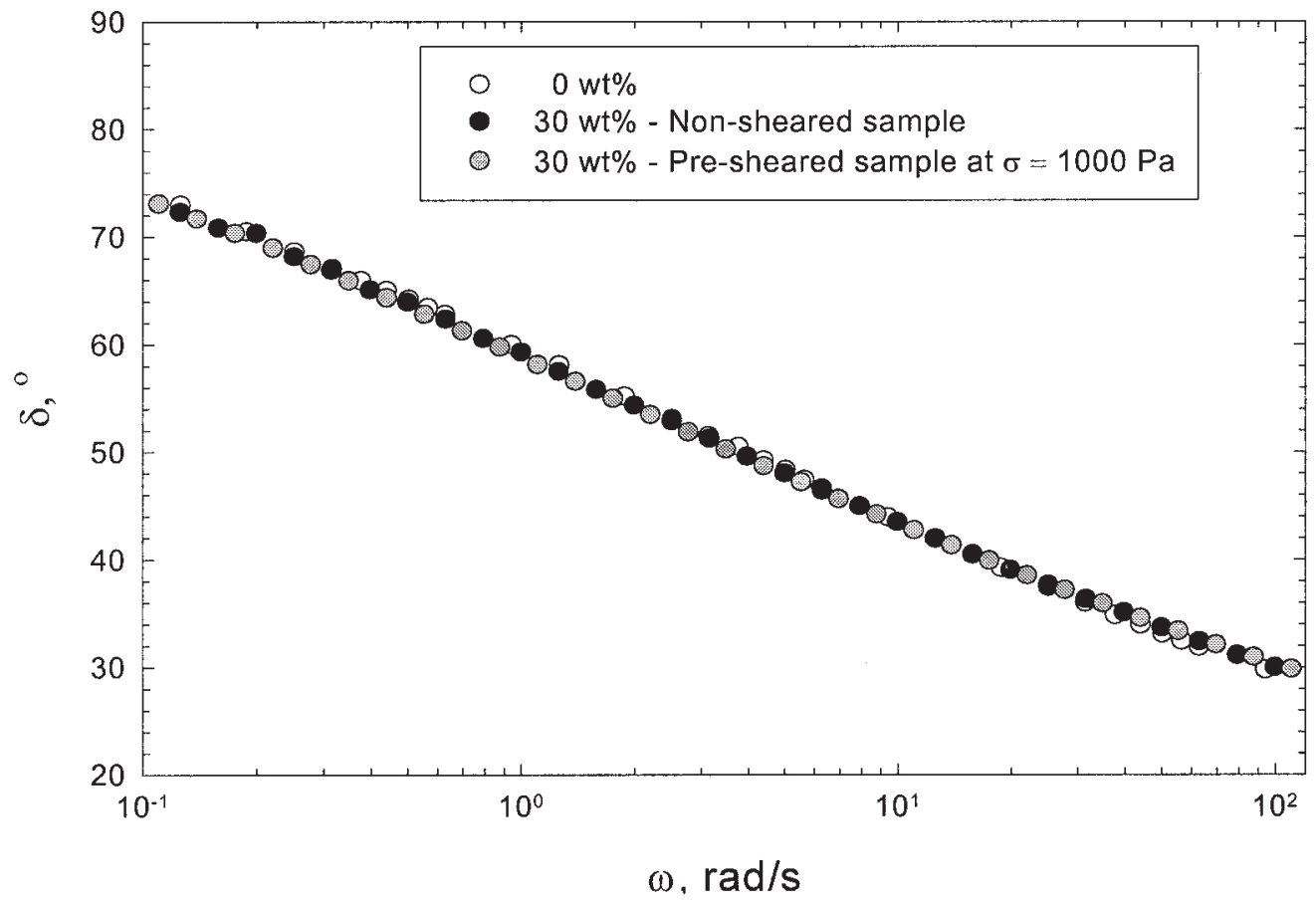

FIG. 5. Out-of-phase angle $\delta$ vs. frequency $\omega$ for neat polypropylene and $30 \mathrm{wt} \%$ fiber reinforced polypropylene; $\mathrm{T}=200^{\circ} \mathrm{C}$.

adhesion to polypropylene are not expected to change within the experimental temperature range. Moreover, the good superposition of the data obtained at different temperatures for the $30 \mathrm{wt} \%$ composite confirms that the flow activation energy is not significantly affected by the fiber content. These data superpose completely on the viscosity data of the matrix,

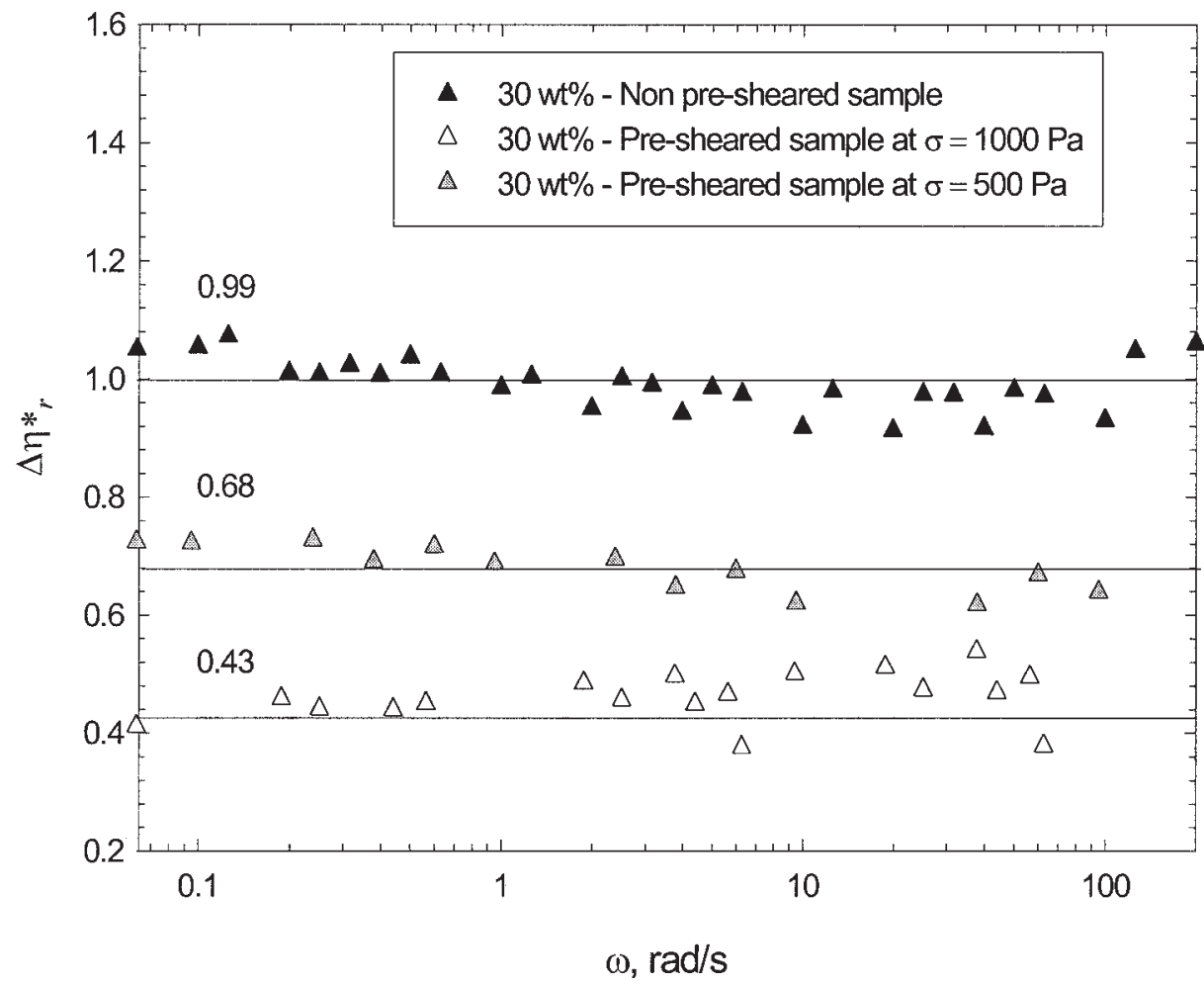

FIG. 6. Effect of pre-shearing on the relative difference of the complex viscosity $\Delta \eta^{*}$, of 30 wt $\%$ fiber reinforced polypropylene; $\mathrm{T}=200^{\circ} \mathrm{C}$. 


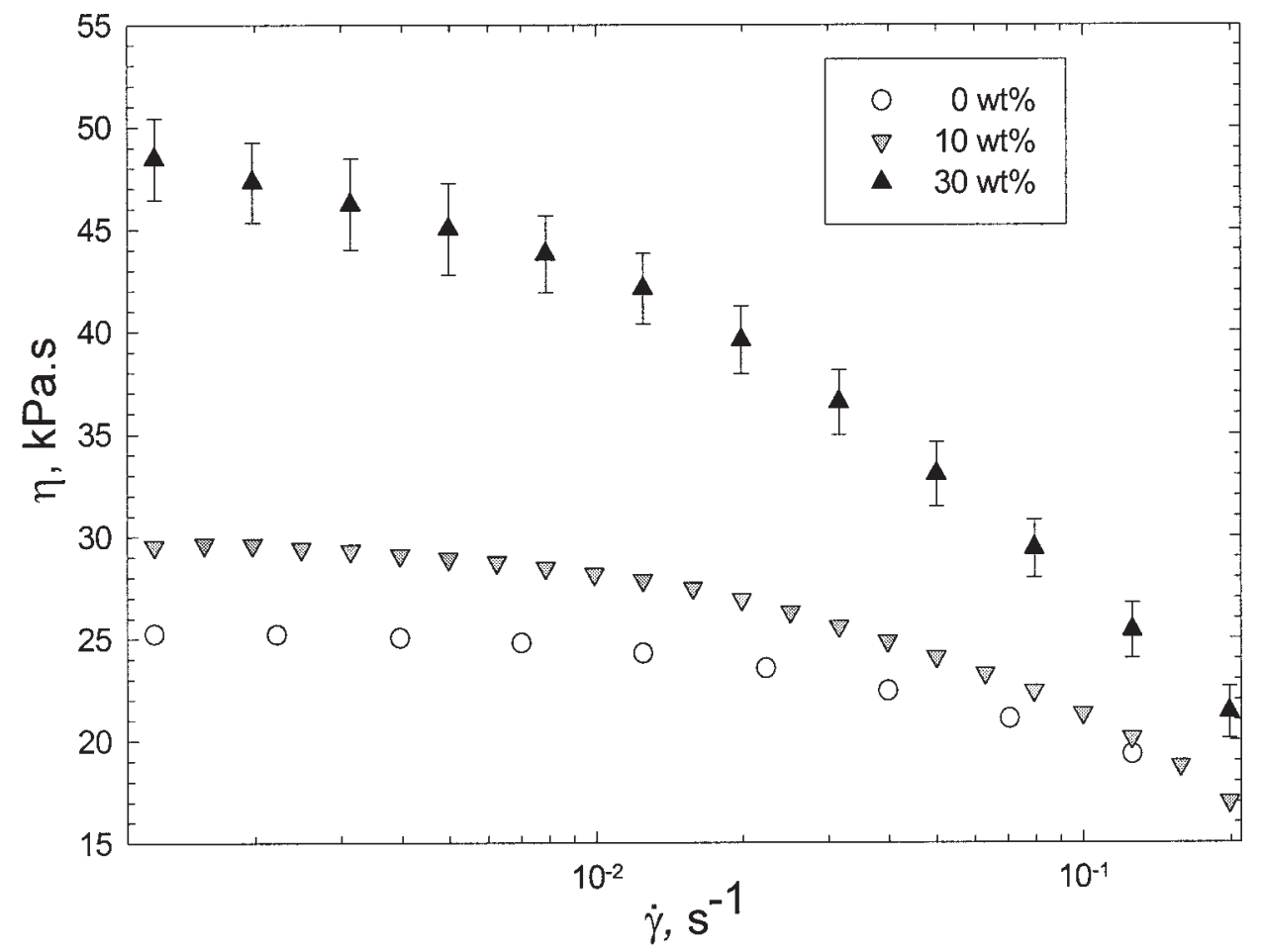

FIG. 7. Viscosity $\eta$ vs. shear rate $\dot{\gamma}$ for reinforced polypropylene with various fiber contents; $\mathrm{T}=200^{\circ} \mathrm{C}$.

indicating that the fiber content has no effect on the shear viscosity at high shear rates. This confirms the findings of Barbosa and Kenny [19] for similar composites. They found that the fibers near the die walls were at a lower concentration and totally oriented in the flow direction.

\section{Cox-Merz Analogy}

The shear and complex viscosities measured with the different devices are compared in Fig. 9 for the neat polypropylene (data multiplied by 0.1 to facilitate the com-

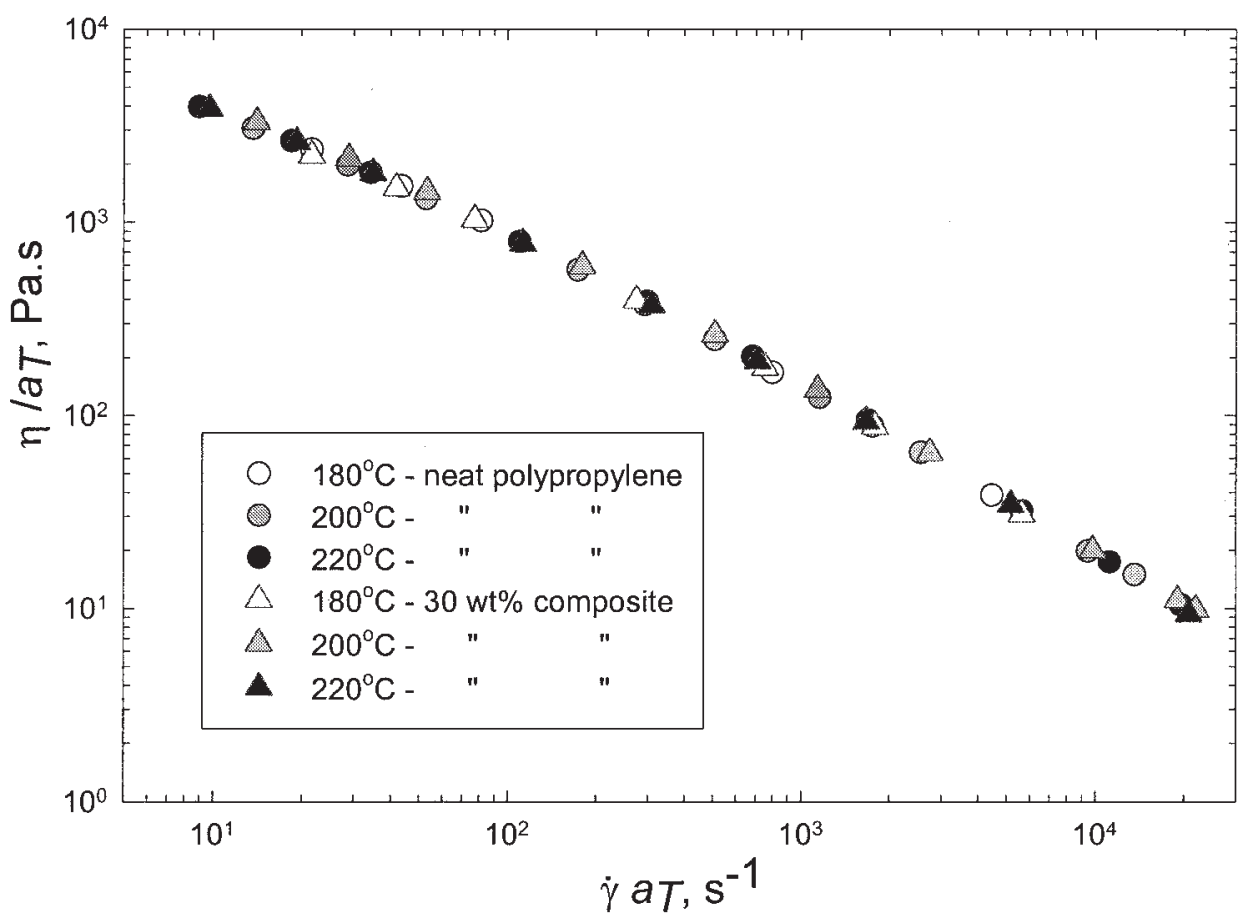

FIG. 8. Master shear viscosity curve for the neat polypropylene and the $30 \mathrm{wt} \%$ composite; slit die, $\mathrm{T}_{0}$ $=200^{\circ} \mathrm{C}$. 


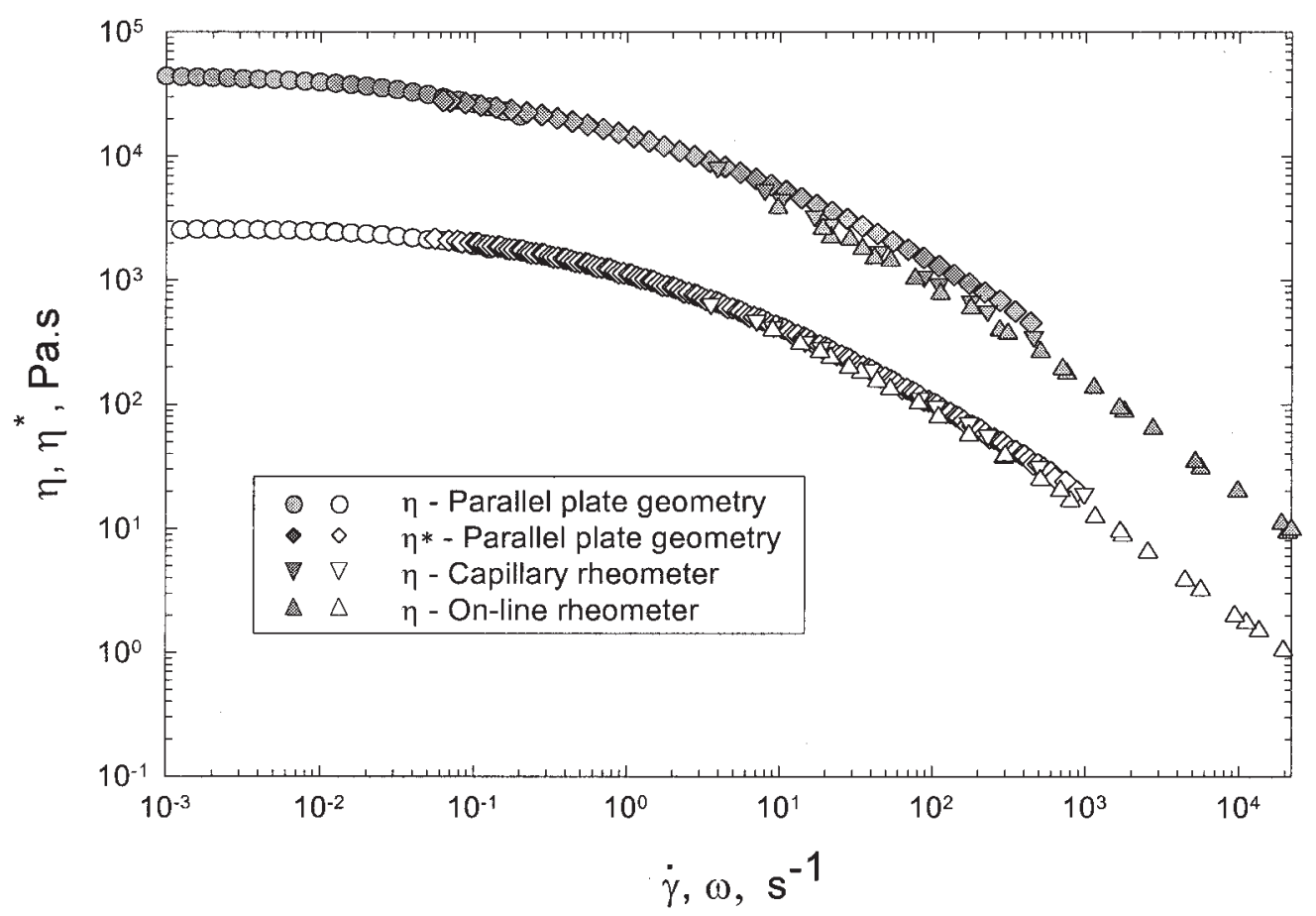

FIG. 9. Shear viscosity and complex viscosity curves of neat polypropylene (unfilled symbols) and $30 \mathrm{wt} \%$ fiber reinforced polypropylene (grey symbols); $\mathrm{T}=200^{\circ} \mathrm{C}$. The data for the neat polypropylene have been multiplied by 0.1 for convenience.

parison) and the $30 \mathrm{wt} \%$ reinforced polypropylene. The Cox-Merz rule is well verified for the neat polypropylene and we note an excellent agreement between the capillary and parallel plate data. The on-line data are slightly lower than the data obtained with the other two rheometers, but the differences are acceptable. For the $30 \mathrm{wt} \%$ PP composite, the Cox-Merz rule is verified for the low frequencies or shear rates, but fails for rates larger than $10 \mathrm{~s}^{-1}$. We should mention that the complex viscosity data presented for the reinforced system have been obtained after pre-shearing at $1000 \mathrm{~Pa}$ up to equilibrium. Consequently, the fiber macrostructure for this measurement was similar to that of the sample at the beginning of the simple shear viscosity measurement with the parallel-plate geometry. The similarity in the fiber macro-structures at low rates explains the superposition of the steady state and dynamic data. Conversely, the divergence at high rates are explained by the more pronounced orientation of the fibers under steady shear flow $[18,19]$. The differences between dynamic and steady shear measurements can also be explained by the presence of a dilute layer induced by the steady shear flow near the wall as outlined by Charrier and Rieger [44] and clearly illustrated by the modeling of Thomasset et al. [45].

\section{First Normal Stress Difference}

The first normal-stress difference, $N_{1}$, was measured at low shear rates $\left(10^{-2}-1 \mathrm{~s}^{-1}\right)$ with the parallel-plate geometry in steady state assuming that the secondary normal stress difference, $N_{2}$, was negligible. Higher shear rate (10
$-10^{5} \mathrm{~s}^{-1}$ ) have been obtained with the on-line rheometer slit die using the Forgacs and Manson correlation [46]:

$$
N_{1}\left(\tau_{w}\right)=P_{\text {exit }}
$$

that is, $N_{1}$ is equal to the pressure at the exit of a slit die referred as $P_{\text {exit }}$. The exit pressure is obtained by extrapolating the measured pressure profile to the exit. We used also the Han correlation [47] given by:

$$
N_{1}=P_{e x i t}\left(1+\frac{d \ln P_{e x i t}}{d \ln \tau_{w}}\right)
$$

which adds a correction for the variation of the exit pressure as a function of the wall stress, $\tau_{W}$. The results are presented in Fig. 10 for the neat polypropylene. We observe that the data obtained from the parallel plate measurements do not extrapolate to the exit pressure data and to the values of the Han correlation. As shown by Choplin and Carreau [48], using a macroscopic mechanical energy balance, the exit viscous dissipation is not negligible as assumed by Forgacs and Manson [46] and Han [47]. Hence, Eqs. 29 and 30 could considerably overpredict the primary normal stress difference.

Laun [49] proposed the following expression to estimate the primary normal stress coefficient, $\psi_{1}$ from dynamic data obtained in the range of $10^{-2}$ to $10^{3} \mathrm{~s}^{-1}$ : 


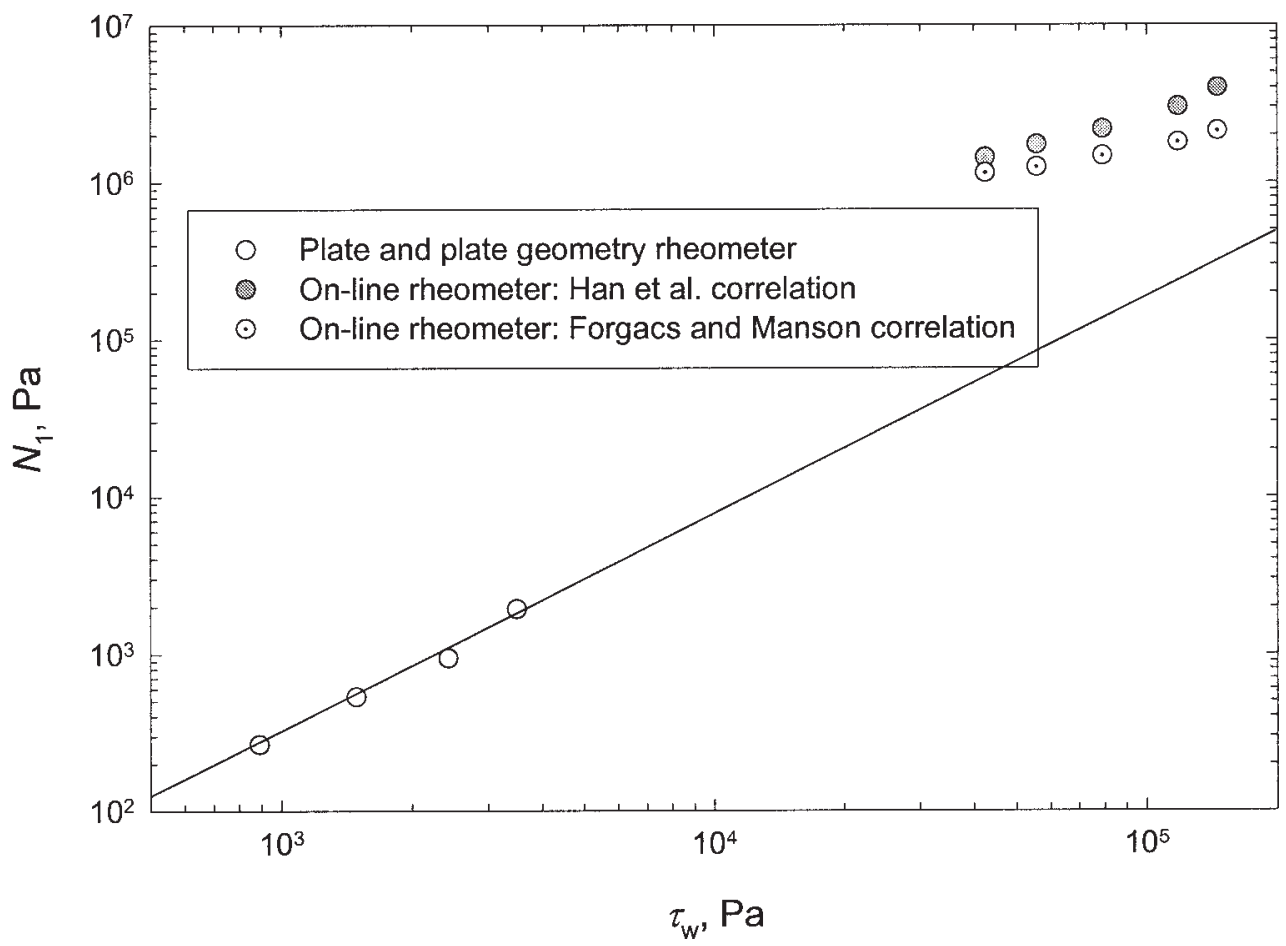

FIG. 10. Primary normal stress difference $\mathrm{N}_{1}$ vs. wall shear stress $\tau_{\mathrm{w}}$ for neat polypropylene; $\mathrm{T}=200^{\circ} \mathrm{C}$ (on-line rheometer and parallel plate geometry).

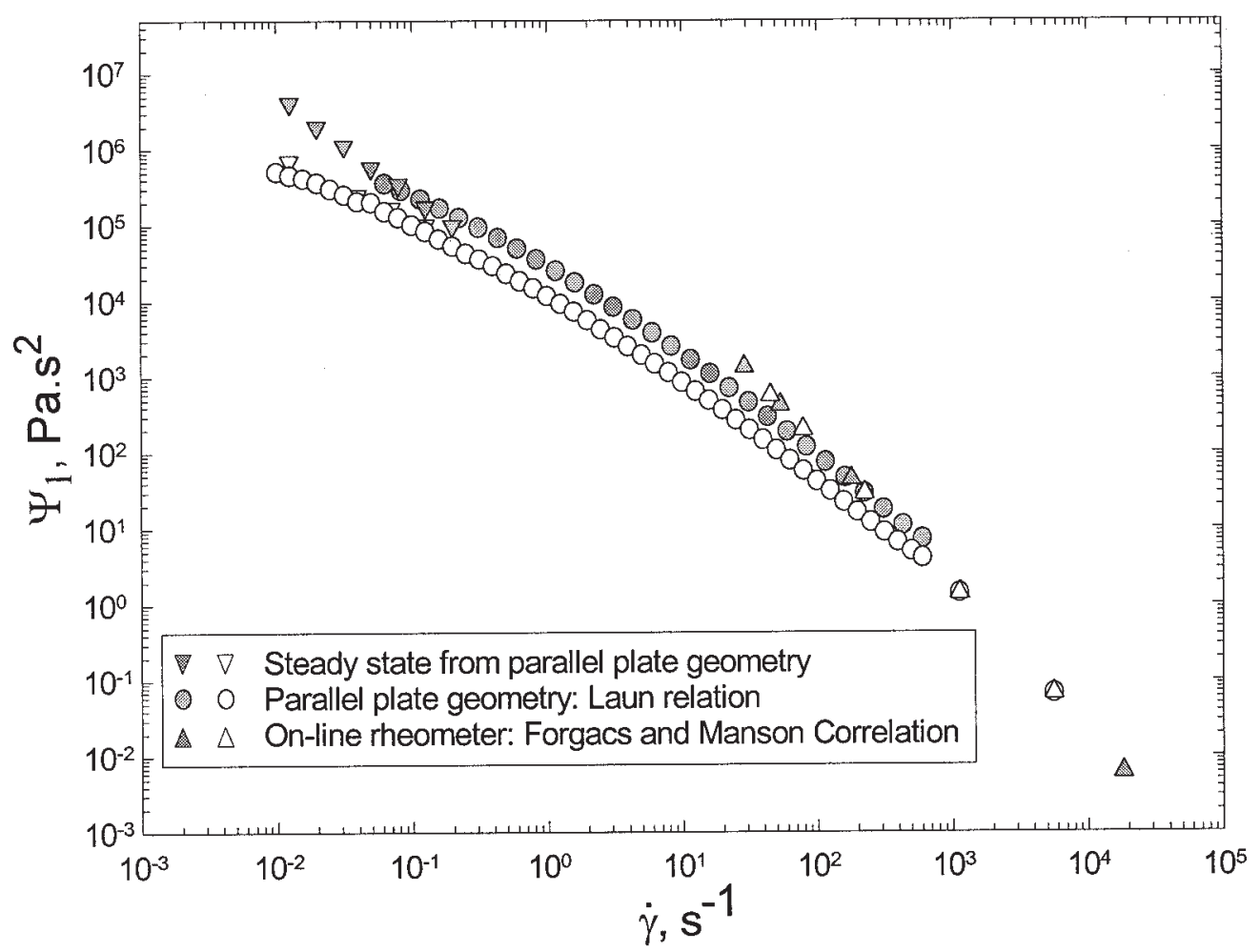

FIG. 11. First normal stress coefficient $\Psi_{1}$ vs. shear rate $\dot{\gamma}$ for neat polypropylene (unfilled symbols) and 30 $\mathrm{wt} \%$ fiber reinforced polypropylene (gray symbols); $\mathrm{T}=200^{\circ} \mathrm{C}$. 


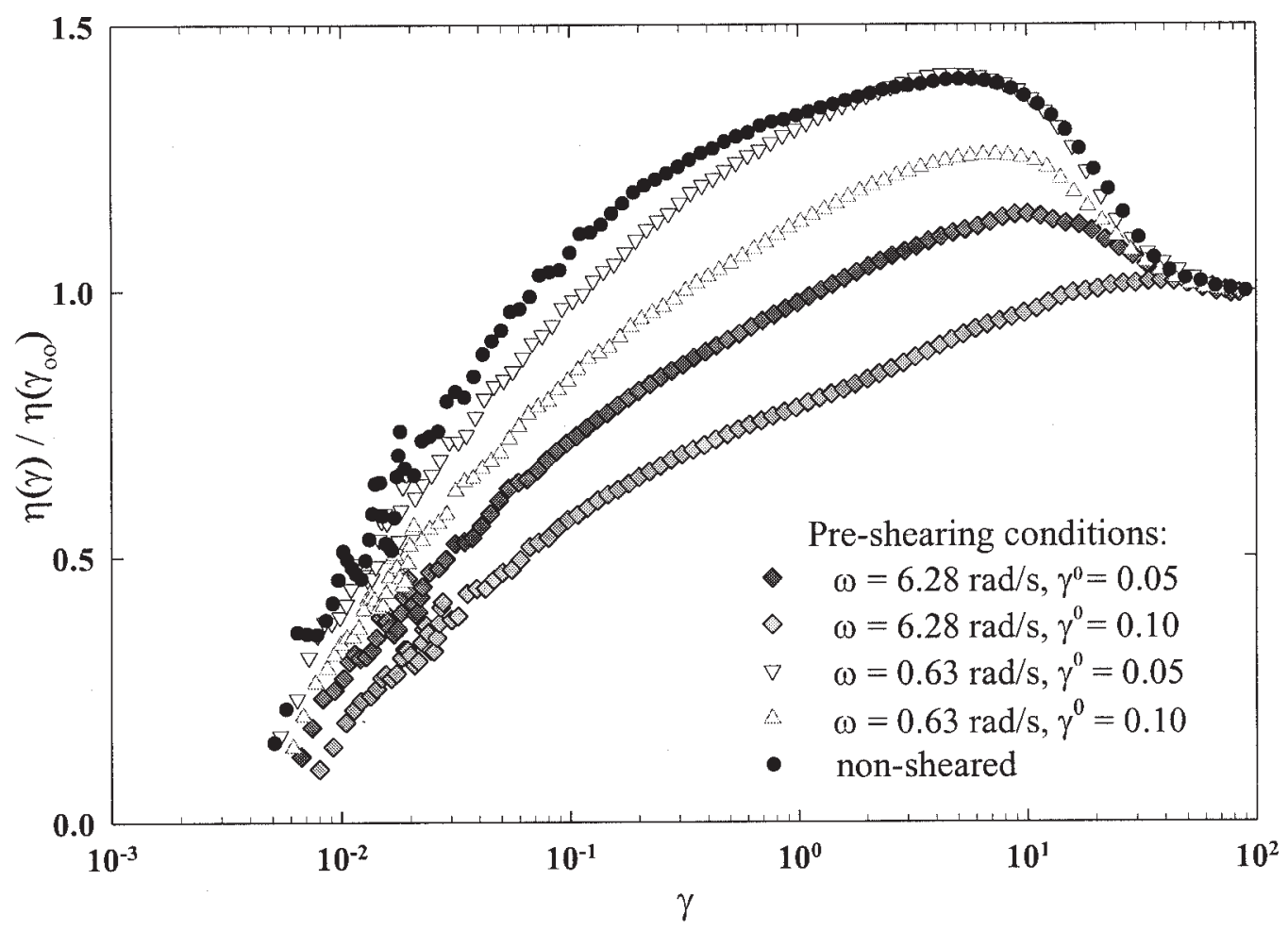

FIG. 12. Effect of dynamic pre-conditioning on the creep viscosity of $30 \mathrm{wt} \%$ fiber reinforced polypropylene, $\eta\left(\gamma_{\infty}\right)$ : viscosity at the equilibrium; $\mathrm{T}=200^{\circ} \mathrm{C}$.

$$
\Psi_{1}(\dot{\gamma}) \equiv-\frac{N_{1}(\dot{\gamma})}{\dot{\gamma}^{2}}=\left.\frac{2 G^{\prime}(\omega)}{\omega^{2}}\left[1+\left(\frac{G^{\prime}}{G^{\prime \prime}}\right)^{2}\right]^{0.7}\right|_{\omega=\dot{\gamma}}
$$

The parallel plate normal stress data and the values of $\psi_{1}$ obtained using Eqs. 29-31 are plotted in Fig. 11 for the neat polypropylene and the $30 \mathrm{wt} \%$ composite. The behavior depicted is similar to that of the shear and complex viscosities. The Laun relation [49] appears to be valid for both the neat polypropylene and the $30 \mathrm{wt} \%$ composite. For very small rates, Eq. 31 reduces to the prediction of an upperconvected Maxwell model [36] with a constant $\psi_{1}$ (zeroshear plateau). The trend of further increases of $\psi_{1}$ for the $30 \%$ composite as the shear rate goes down to very small values is probably due to fiber-fiber interactions that become dominant, as observed by Sepehr et al. [25] for suspensions of the same glass fibers in a Newtonian matrix. The primary normal coefficient is somewhat larger for the $30 \mathrm{wt} \%$ composite than for the neat polypropylene, but as observed for the steady-shear viscosity (Fig. 7) the differences decrease at high shear rates. If we recall that the fiber orientation increases with shear rate [18] and consequently fiber-fiber interactions decrease, this observation supports the assertion of Zirnsak et al. [23] and Sepehr et al. [25] who claim that the increase of the primary normal stresses reflect the fiber-fiber interactions. The two correlations based on the exit pressure (Eqs. 29 and 30) overpredict the primary normal stress coefficient, in the range covered by the Laun relation [49], but the Forgacs and Manson correlation [46] appears to be reasonable at large rates. However, we need to obtain normal stress data at high rates using a more reliable method to verify the Laun empirical relation.

\section{Transient Behavior}

The complex transient behavior for creep and stress growth measurements of the same reinforced polypropylene samples has been presented and discussed in Sepehr et al. [50]. Here, we illustrate in Fig. 12 the effect of a dynamic pre-conditioning on the creep data in terms of the instantaneous viscosity as a function of strain, $\gamma$ for the $30 \mathrm{wt} \%$ reinforced polypropylene. For the preconditioning, various frequency and strain amplitude conditions were applied during one hour. Immediately after the pre-conditioning, creep experiments were conducted for an applied shear stress of $600 \mathrm{~Pa}$. Without pre-conditioning, the creep viscosity of the fiber reinforced suspension exhibited a large overshoot, due to the fiber macro-structure evolution [10, 34, 35, 51, 52]. The amplitude of this overshoot was reduced by the preconditioning, especially at large strain amplitude and high frequency. The overshoot almost vanished for a strain amplitude of 0.1 and frequency of $6.28 \mathrm{rad} / \mathrm{s}$. The observations of Fig. 12 are explained by the fact that a large amplitude oscillatory shear affects the fiber-fiber interactions and leads to a shear aligned fiber macrostructure, as previously shown by Kim and Song [20]. 


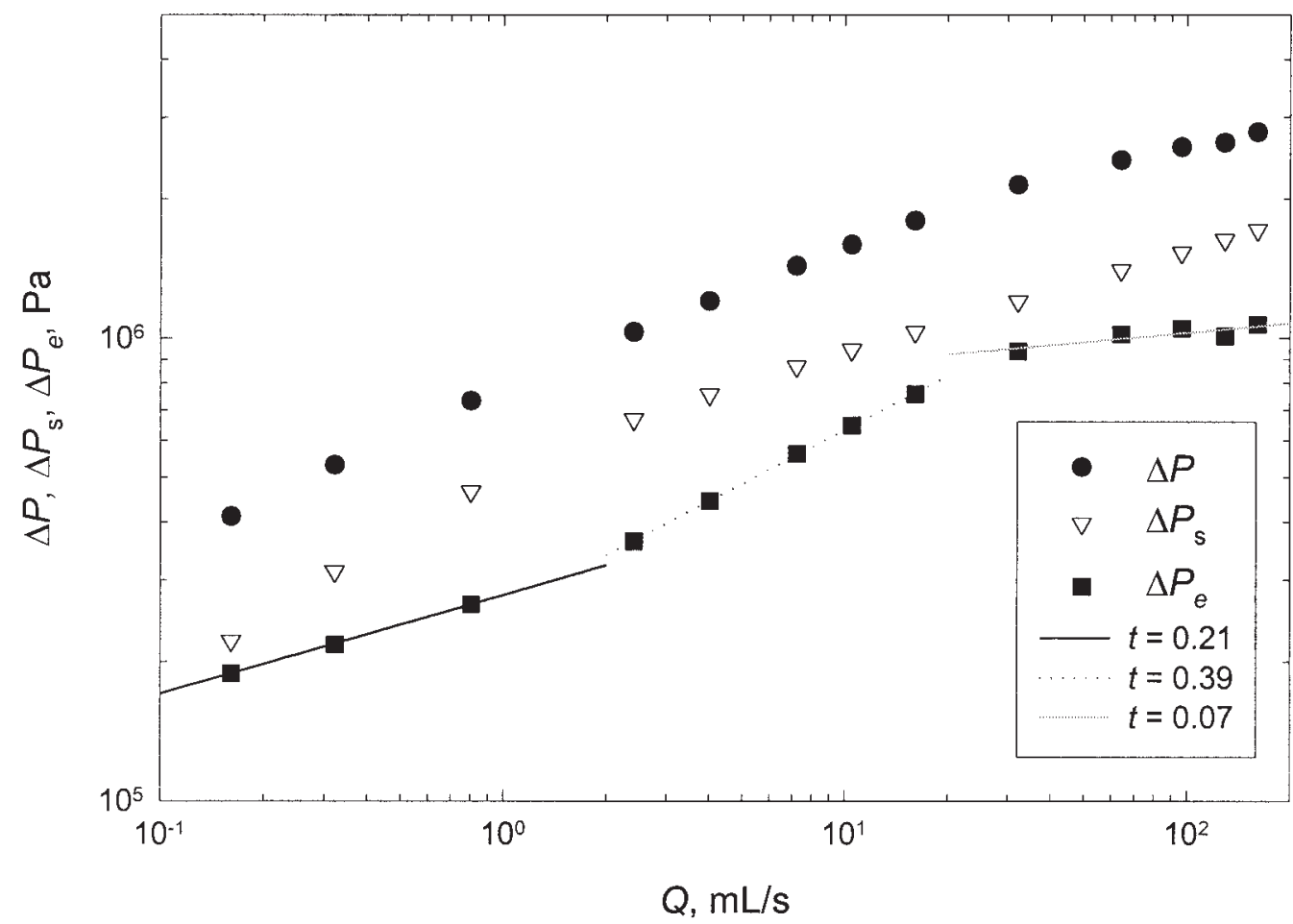

FIG. 13. Total pressure drop and contributions of the shear and extensional components vs. flow rate $\mathrm{Q}$ for the neat polypropylene; converging die "a"; $\mathrm{T}=200^{\circ} \mathrm{C}$.

\section{Apparent Extensional Viscosity}

Figure 13 reports the total pressure drop and calculated shear and extensional contributions for the neat polypropylene as functions of the flow rate for hyperbolic die $(a)$. The extensional contributions were calculated using the experimentally determined pressure drops and the calculated shear contributions using Eq. 12 or the first term of Eq. 16. For the shear rate range experimentally covered in the converging dies, the polymer does not obey a simple powerlaw expression. Three zones were then defined for which we used the following power-law parameters:

$$
\begin{aligned}
& \dot{\gamma} \geq 100 \mathrm{~s}^{-1} \Rightarrow n=0.22 \text { and } m=3.04 \times 10^{4} \mathrm{~Pa} \cdot \mathrm{s}^{n} \\
& 10 \mathrm{~s}^{-1} \leq \dot{\gamma}<100 \mathrm{~s}^{-1} \Rightarrow n=0.40 \text { and } \\
& \quad m=1.516 \times 10^{4} \mathrm{~Pa} \cdot \mathrm{s}^{n} \\
& \dot{\gamma}<10 \mathrm{~s}^{-1} \Rightarrow n=0.60 \text { and } m=1.014 \times 10^{4} \mathrm{~Pa} \cdot \mathrm{s}^{n}
\end{aligned}
$$

For each flow rate, the converging die was separated in different zones for which the appropriate power-law expression was used, based on the calculated shear rate at the wall. The extensional flow contribution is shown in Fig. 13 to be significant, representing about $40 \%$ of the total pressure drop for the shorter converging die $(a)$. If the total pressure drop is believed to be accurate within a few percents, the accuracy of the extensional contribution is, however, not better than $\pm 15 \%$. The extensional contributions have been described by three different power-law expressions for cal- culating the apparent extensional viscosity using the Binding method.

The apparent extensional viscosity, $\eta_{e}$, of the neat polypropylene estimated for the shorter converging die (a) using the Cogswell and the Binding analyses are presented in Fig. 14 (error bars indicating estimated errors). The complex and shear viscosity data are shown to illustrate some differences in the behavior. The Binding analysis ( $E q$. 16) takes into account the strain dependence of the extensional viscosity as well as that of the shear viscosity. As mentioned above, the parameter $t$ was obtained from the $\log -\log$ plot of the extensional contribution to the pressure drop vs. flow rate in three zones as shown in Fig. 13. We took into account the variations of the power-law parameters for the shear viscosity, as we did for calculating the contributions of the shear viscosity to the pressure drop. The apparent extensional viscosity values calculated using the Binding method are presented in Fig. 14 as a function of the extensional rate at the centerline of the converging die compared to the average extensional rate for the calculations based on the Cogswell method. The apparent extensional viscosity for the Binding analysis is probably more meaningful, but the overall trend in both sets of calculated values is the same, although the values based on the Binding method are somewhat smaller. For simplicity reasons, we chose to present only the extensional data for the $30 \%$ composite based on the Cogswell method.

For the data presented in Fig. 14, based on the Cogswell method, the Trouton ratio, $T_{R}$, defined as $\eta_{e} / \eta$, was evalu- 


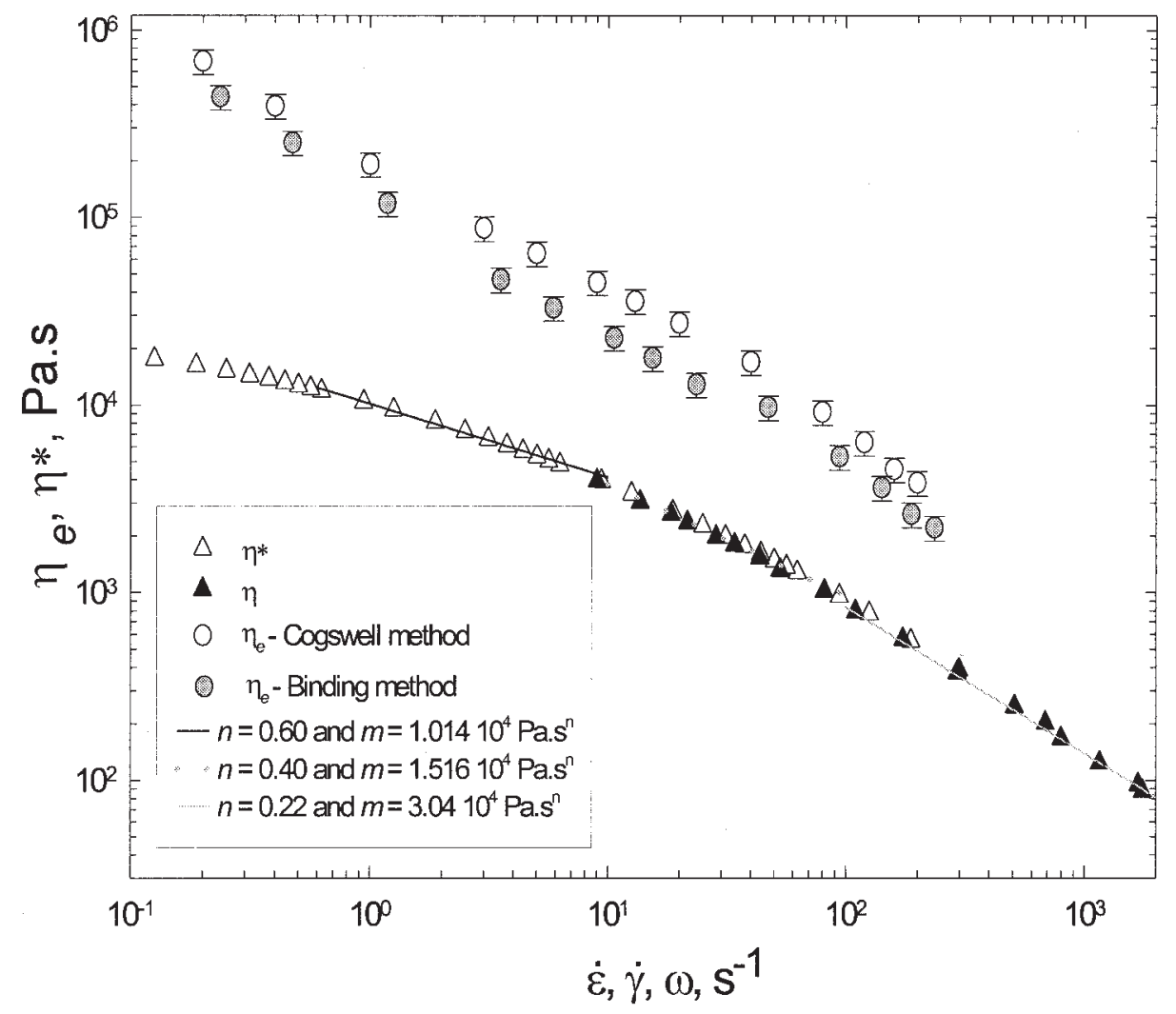

FIG. 14. Apparent extensional viscosity $\eta_{\mathrm{e}}$ calculated using the Cogswell and Binding methods for neat polypropylene; converging die "a"; $\mathrm{T}=200^{\circ} \mathrm{C}$. The simple shear and complex viscosity data are shown for comparison.

ated at the same value of the second invariant of the rateof-deformation tensor, i.e., at $\bar{\gamma}=\dot{\gamma}=2 \dot{\varepsilon}$. The ratio was found to be around 40 at low strain rates, and decreased rapidly as the extensional rate increases from 0.2 to $200 \mathrm{~s}^{-1}$ to reach a value of 4 , which is the theoretical Trouton ratio for a Newtonian fluid in planar extension. Our results at low strain rates are in agreement with those of Binding et al. [53] for another polypropylene. However, the value of the Trouton ratio of 4 at large strain rates is much smaller than that reported by Binding et al.

The corresponding data for the reinforced polypropylenes containing 10 and $30 \mathrm{wt} \%$ are compared to the neat polypropylene data in Fig. 15. For these results, we use only the simpler Cogswell method and data obtained using the shorter converging die, which induces higher rates and for which the extension flow contributions are the largest. The complex viscosity data of the neat polypropylene are also shown for comparison. We observe that the apparent extensional viscosity of the composites increases slightly with fiber content. The relative extensional viscosity increase is defined by:

$$
\Delta \eta_{e r}(\dot{\varepsilon})=\left.\frac{\eta_{\text {esuspension }}-\eta_{\text {ematrix }}}{\eta_{\text {ematrix }}}\right|_{\dot{\varepsilon}}
$$

For the data presented in Fig. $15, \Delta \eta_{e r}$ was found to be almost independent of the extensional rate. It is equal to 35 and $5 \%$ for the 30 and $10 \mathrm{wt} \%$ reinforced polypropylenes, respectively. The 5\% increase for the $10 \mathrm{wt} \%$ composite is not significant considering the experimental uncertainty. The effect of fiber content on the extensional properties is considerably less compared to that observed for dynamic data (Fig. 6).

The Goddard model predicts a relative stress, $\Delta \sigma_{r}$ (= $\left.\Delta \eta_{e r}\right)$, equal to 0.54 and 0.22 for the 30 and $10 \mathrm{wt} \%$ reinforced systems, respectively. These results are 1.5 and 4.4 times larger than the values based on the experimental data of Fig. 15. The same unsatisfactory agreement was found by Goddard [54] between his non-Newtonian theory and the experimental data of Chan et al. [11]. According to Goddard, the lack of alignment of the fibers in the flow direction and the lack of adhesion between the fibers and the matrix were the most plausible causes of this discrepancy. The lack of fiber orientation as observed from micrographs of samples taken at the exit of the converging section appears to be the reason for the difference between the model prediction and our data.

\section{CONCLUDING REMARKS}

We have reported a rather complete rheological characterization of a commercial glass fiber reinforced polypropylene, using conventional rheometers and a novel on-line rheometer mounted on an injection molding machine. The 


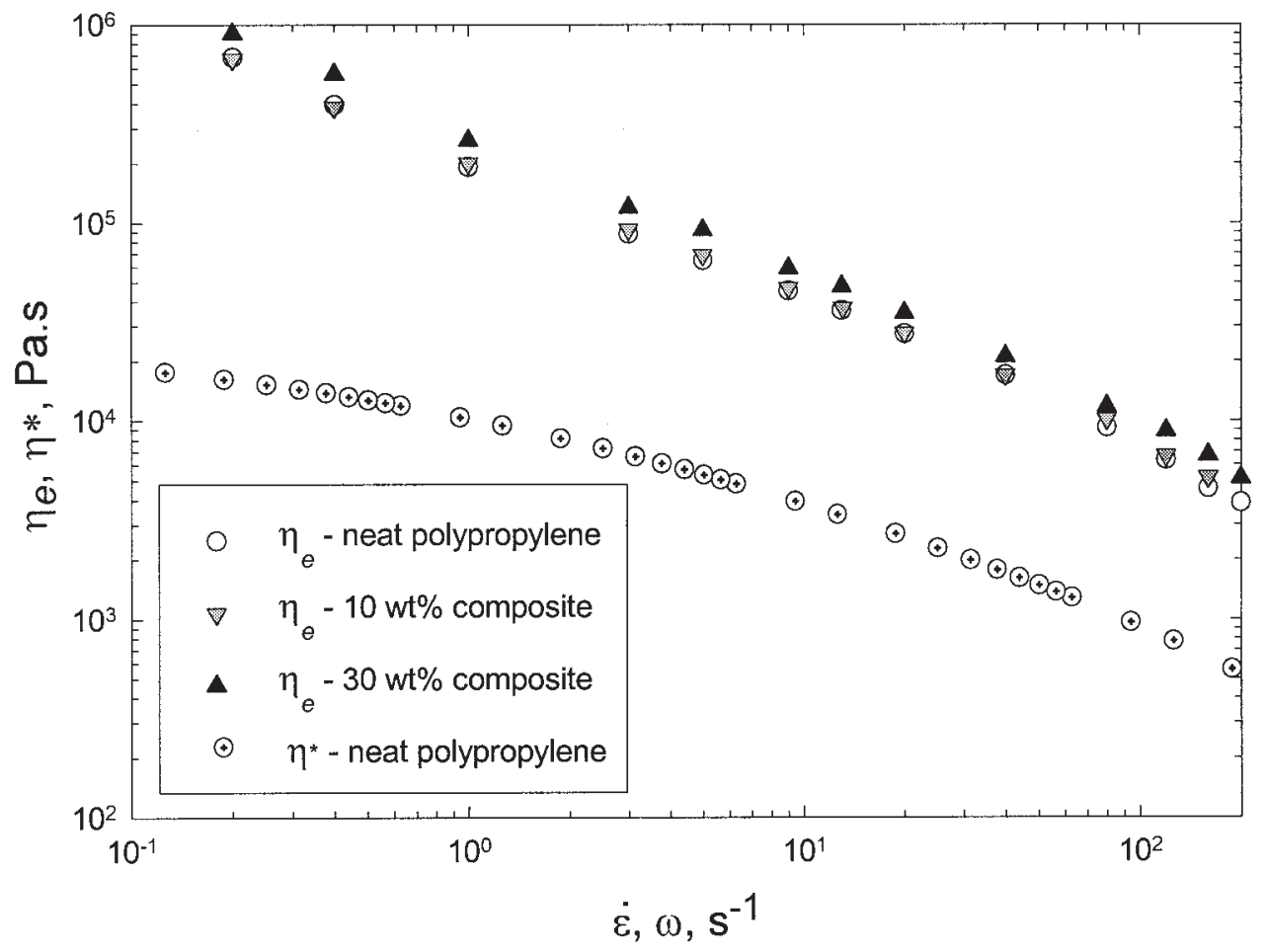

FIG. 15. Apparent extensional viscosity $\eta_{\mathrm{e}}$ for reinforced polypropylene with various fiber contents using the Cogswell method and converging die "a"; $\mathrm{T}=200^{\circ} \mathrm{C}$. The complex viscosity $\eta^{*}$ data for neat polypropylene are shown for comparison.

experimental conditions were comparable to those encountered in polymer processing. The on-line rheometer consisted of a slit die and planar hyperbolic converging and diverging dies. The apparent extensional properties were obtained from the pressure drop in the converging die using the Cogswell [1] and Binding [2] analyses. The steady-shear viscosity could be obtained from the pressure profile along the slit die measured by three flushed-mounted transducers.

All the dynamic properties as well as the steady shear viscosity were found to increase with fiber content. However, the loss angle was shown to be independent of fiber content, indicating that the elasticity of the composites was not affected by the presence of fibers. The enhancement of the steady shear viscosity was more important at very low strain rates, mainly for the $30 \mathrm{wt} \%$ composite. Moreover, the rheological properties were affected by the fiber macrostructure or fiber orientation. Pre-shearing was shown to decrease the complex viscosity and the viscosity overshoot during transient experiments, respectively. The Cox-Merz rule was found to be valid for the neat polypropylene, but important deviations were observed for the composites at large rates, and these have been attributed to fiber orientation induced by large shear rates.

The primary normal stress difference was evaluated using the parallel plate geometry and empirical correlations based on the dynamic data, as well as exit pressure data from the slit die. The Laun relation [49] based on dynamic data gave a satisfactory description of the primary normal stress coefficient for the neat polypropylene, whereas the correlations based on the exit pressure overestimated the normal stresses, except possibly for very large shear rates. The Laun relation appeared to well describe the normal stress data for the $30 \%$ composite, except at very low shear rates where the fiber-fiber interactions were dominant and responsible for larger normal stresses.

The apparent extensional viscosity of the neat polypropylene was found to exhibit a similar behavior as the shear or complex viscosity, but the extensional viscosity of the polypropylene was found to be much larger than the shear viscosity at low strain rates. The Trouton ratio of about 40 decreased rapidly with increasing strain rate down to the value of 4 at $200 \mathrm{~s}^{-1}$. The extensional viscosity of the composites was also found to be close to that of the matrix, with values of 35 and 5\% larger for the 30 and $10 \mathrm{wt} \%$ reinforced polypropylenes, respectively. These values are much lower than those predicted by the Goddard [3] model.

\section{ACKNOWLEDGEMENTS}

The materials used in the study were provided by Basell, for which the authors wish to thank Dr. G. Krotkine.

\section{REFERENCES}

1. F.N. Cogswell, Polym. Eng. Sci., 12(1), 64 (1972).

2. D.M. Binding, J. Non-Newt. Fluid Mech., 7, 173 (1988). 
3. J.D. Goddard, J. Non-Newt. Fluid Mech., 78(1), 177 (1976).

4. N.-J. Lee and J. Jang, Compos. Sci. Technol., 57(12), 1559 (1997).

5. S.Y. Fu, X. Hu, and C.Y. Yue, Mater. Sci. Research Int., 5(2), 74 (1999).

6. S. Nagae, Y. Otsuka, M. Nishida, T. Shimizu, T. Takeda, and S. Yumitori, J. Mater. Sci. Lett., 14(17), 1234 (1995).

7. M. Arroyo, M.A. Lopez-Manchado, and F. Avalos, Polymer, 38(22), 5587 (1997).

8. S. Goto, H. Nagazono, and H. Kato, Rheol. Acta, 25, 119 (1986).

9. T. Kitano and T. Kataoka, Rheol. Acta, 20, 390 (1981).

10. E. Gananie and R.L. Powell, J. Rheol., 30(5), 995 (1986).

11. Y. Chan, J.L. White, and Y. Oyanagi, J. Rheol., 22(5), 507 (1978).

12. L. Czarnecki and J.L. White, J. Appl. Polym. Sci., 25, 1217 (1980).

13. T. Kitano, T. Kataoka, and Y. Nagatsuka, Rheol. Acta, 23, 20 (1984).

14. J.P. Greene and J.O. Wilkes, Polym. Eng. Sci., 35(21), 1670 (1995).

15. W.J. Milliken, M. Gottlieb, A.L. Graham, L.A. Mondy, and R.L. Powell, J. Fluid Mech., 202, 217 (1989).

16. L.A. Mondy, T.G. Morisson, and A.L. Graham, Int. J. Multiphase Flow, 16, 651 (1990).

17. R.O. Maschmeyer and C.T. Hill, Trans. Sot. Rheol., 21(2), 183 (1977).

18. R.J. Crowson, M.J. Folkes, and P.F. Bright, Polym. Eng. Sci., 20(14), 925 (1980).

19. S.E. Barbosa and J.M. Kenny, Polym. Eng. Sci., 40(1), 11 (2000).

20. K.J. Kim and J.H. Song, J. Rheol., 41(5), 1061 (1997).

21. O.G. Harlen and D. Koch, J. Non-Newt. Fluid Mech., 73, 81 (1997).

22. M.P. Petrich, M. Chaouche, D.L. Koch, and C. Cohen, J. Non-Newt. Fluid Mech., 91, 1 (2000).

23. M.A. Zirnsak, D.U. Hur, and D.V. Boger, J. Non-Newt. Fluid Mech., 54, 153 (1994).

24. S.E. Barbosa and T. Kataoka, Soc. Plast. Eng. ANTEC, 3116 (1995)

25. M. Sepehr, P.J. Carreau, G. Ausias, and M. Moan, J. Rheol., 48(5), 1023 (2004).

26. W.M. Lobe and J.L. White, Polym. Eng. Sci., 19(9), 617 (1979).

27. H. Tanaka and J.L. White, Polym. Eng. Sci., 20(14), 949 (1980).
28. G.-G. Lin and M.-C. Hu, Adv. Polym. Tech., 16(3), 199 (1997).

29. H. Münstedt, Rheol. Acta, 14, 1077 (1975).

30. Y. Ide and J.L. White, J. Appl. Polym. Sci., 22(4), 1061 (1978).

31. S.M. Dinh and R.C. Armstrong, J. Rheol., 28(3), 207 (1984).

32. E.S.G. Shaqfeh and G.H. Fredrickson, Phys. Fluids A, 2, 7 (1990).

33. G.K. Batchelor, J. Fluid Mech., 46, 813 (1971).

34. G. Ausias, J.F. Agassant, and M. Vincent, J. Rheol., 36(4), 525 (1992).

35. M.A. Bibbo, S.M. Dinh, and R.C. Armstrong, J. Rheol., 29(6), 905 (1985).

36. P.J. Carreau, D.D. Kee, and R.P. Chabra, Rheology of Polymeric Systems: Principles and Applications, Hanser Publishers, Munich (1997).

37. H.C. Kim, A. Pendse, and J.R. Collier, J. Rheol., 38(4), 831 (1994).

38. D.F. James, G.M. Chandler, and S.J. Armour, J. Non-Newt. Fluid Mech., 35, 421 (1990).

39. A. Yoshimura and R.K. Prud'homme, J. Rheol., 31(1), 53 (1988).

40. P. Mourniac, J.F. Agassant, and B. Vergnes, Rheol. Acta, 31(6), 565 (1992).

41. A. Hashemi, A. Aït-Kadi, and P.J. Carreau, J. Polym. Eng., 23(4), 281 (2003).

42. T. Kitano, T. Kataoka, and Y. Nagatsuka, Rheol. Acta, 23, 408 (1984).

43. H.M. Laun and H. Schuch, J. Rheol., 33, 119 (1989).

44. J.M. Charrier and J.M. Rieger, Fibre Sci. Technol., 7, 161 (1974).

45. J. Thomasset, M. Grmela, and P.J. Carreau, J. Non-Newt. Fluid Mech., 73, 195 (1997).

46. O.L. Forgacs and S.G. Manson, J. Colloid Sci., 14, 457 (1959).

47. C.D. Han, Trans. Sot. Rheol., 18(1), 163 (1974)

48. L. Choplin and P.J. Carreau, J. Non-Newt. Fluid Mech., 9, 119 (1981).

49. H.M. Laun, J. Rheol., 30(3), 459 (1986).

50. M. Sepehr, P.J. Carreau, and G. Ausias, J. Non-Newt. Fluid Mech., 123(1), 19 (2004)

51. H.M. Laun, Colloid Polym. Sci., 262(4), 257 (1984).

52. D.M. Jones, K. Walters, and P.R. Williams, Rheol. Acta, 26, 20 (1987).

53. D.M. Binding, M.A. Couch, and K. Walters, J. Non-Newt. Fluid Mech., 79(2-3), 137 (1998).

54. J.D. Goddard, J. Rheol., 22, 615 (1978). 